\title{
Calcitonin controls bone formation by inhibiting the release of sphingosine 1-phosphate from osteoclasts
}

Johannes Keller ${ }^{1}$, Philip Catala-Lehnen ${ }^{1}$, Antje K. Huebner ${ }^{1,2}$, Anke Jeschke ${ }^{1}$, Timo Heckt ${ }^{1}$, Anja Lueth ${ }^{3}$, Matthias Krause ${ }^{1}$, Till Koehne ${ }^{1}$, Joachim Albers ${ }^{1}$, Jochen Schulze ${ }^{1}$, Sarah Schilling ${ }^{1}$, Michael Haberland ${ }^{1}$, Hannah Denninger ${ }^{1}$, Mona Neven ${ }^{1}$, Irm Hermans-Borgmeyer ${ }^{4}$, Thomas Streichert ${ }^{5}$, Stefan Breer ${ }^{1}$, Florian Barvencik ${ }^{7}$, Bodo Levkau ${ }^{6}$, Birgit Rathkolb ${ }^{7,8}$, Eckhard Wolf ${ }^{7}$, Julia Calzada-Wack ${ }^{9}$, Frauke Neff ${ }^{9}$, Valerie Gailus-Durner ${ }^{8}$, Helmut Fuchs ${ }^{8}$, Martin Hrabě de Angelis ${ }^{8,10,11}$, Susanne Klutmann ${ }^{12}$, Elena Tsourdi ${ }^{13}$, Lorenz C. Hofbauer ${ }^{13}$, Burkhard Kleuser ${ }^{3}$, Jerold Chun ${ }^{14}$, Thorsten Schinke ${ }^{1} \&$ Michael Amling ${ }^{1}$

The hormone calcitonin (CT) is primarily known for its pharmacologic action as an inhibitor of bone resorption, yet CT-deficient mice display increased bone formation. These findings raised the question about the underlying cellular and molecular mechanism of CT action. Here we show that either ubiquitous or osteoclast-specific inactivation of the murine CT receptor (CTR) causes increased bone formation. CT negatively regulates the osteoclast expression of Spns2 gene, which encodes a transporter for the signalling lipid sphingosine 1-phosphate (S1P). CTR-deficient mice show increased S1P levels, and their skeletal phenotype is normalized by deletion of the S1P receptor $\mathrm{STP}_{3}$. Finally, pharmacologic treatment with the nonselective S1P receptor agonist FTY720 causes increased bone formation in wild-type, but not in $\mathrm{STP}_{3}$-deficient mice. This study redefines the role of $\mathrm{CT}$ in skeletal biology, confirms that S1P acts as an osteoanabolic molecule in vivo and provides evidence for a pharmacologically exploitable crosstalk between osteoclasts and osteoblasts.

\footnotetext{
${ }^{1}$ Department of Osteology and Biomechanics, University Medical Center Hamburg-Eppendorf, 20246 Hamburg, Germany. ${ }^{2}$ Institute of Human Genetics, University Hospital Jena, 07743 Jena, Germany. ${ }^{3}$ Institute of Nutritional Science, University of Potsdam, 14469 Potsdam, Germany. ${ }^{4}$ Center for Molecular Neurobiology, University of Hamburg, 20251 Hamburg, Germany. ${ }^{5}$ Institute of Clinical Chemistry, University Medical Center Hamburg-Eppendorf, 20246 Hamburg, Germany. ${ }^{6}$ Institute of Pathophysiology, University Hospital Essen, 45122 Essen, Germany. ${ }^{7}$ Institute of Molecular Animal Breeding and Biotechnology, Gene Center, Ludwig-Maximilian-University, 81377 Munich, Germany. ${ }^{8}$ German Mouse Clinic, Institute of Experimental Genetics, Helmholtz Center Munich, 85764 Neuherberg, Germany. ${ }^{9}$ German Mouse Clinic, Institute of Pathology, Helmholtz Center Munich, 85764 Neuherberg, Germany. ${ }^{10}$ Center of Life and Food Sciences Weihenstephan, Technische Universität München, 85354 Freising, Germany. ${ }^{11}$ German Center for Diabetes Research, 85764 Neuherberg, Germany. ${ }^{12}$ Department of Nuclear Medicine, University Medical Center Hamburg-Eppendorf, 20246 Hamburg, Germany.

${ }^{13}$ Department of Medicine III, Dresden University Medical Center, 01307 Dresden, Germany. ${ }^{14}$ Scripps Research Institute, La Jolla, California 92937, USA. Correspondence and requests for materials should be addressed to M.A. (email: amling@uke.de).
} 
O steoporosis represents a major public health problem, not only because of its high prevalence, but also because osteoporotic fractures are associated with high morbidity and mortality. At the cellular level, osteoporosis is explained by imbalanced bone remodelling, a physiologically relevant homeostatic process mediated through bone-resorbing osteoclasts and bone-forming osteoblasts ${ }^{1}$. On the basis of their cellular differences, there are two distinct therapeutic options to treat osteoporosis, either osteoclast inhibition (anti-resorptive) or osteoblast activation (osteoanabolic). Currently, the vast majority of patients are medicated by anti-resorptive means, and there is only one osteoanabolic treatment option so far, daily injection of parathyroid hormone $(\mathrm{PTH})$ or a PTH fragment ${ }^{2}$. Since a long-term blockade of bone remodelling may have adverse effects on skeletal integrity, one of the major goals of skeletal research is to identify novel target proteins for osteoanabolic medication.

One of the hormones considered to influence bone remodelling is calcitonin (CT), which was discovered more than 50 years ago as a calcium-lowering factor produced by thyroidal $\mathrm{C}$ cells $^{3,4}$. CT is proteolytically released from procalcitonin (PCT), representing a human sepsis biomarker potentially enhancing sepsis severity 5,6 . CT has been shown to exert its effects through the CT receptor (CTR), a serpentine protein expressed at high levels in kidney and hypothalamus ${ }^{7,8}$. In bone, CT exclusively binds to osteoclasts, exhibiting the highest CTRdensity, and causes cessation of their activity. This anti-resorptive effect is especially pronounced in studies employing salmon $\mathrm{CT}$, displaying a 50-fold higher potency than mammalian $\mathrm{CT}^{9,10}$. On the basis of these findings, CT was considered to represent the functional counterpart to $\mathrm{PTH}$, which physiologically activates bone resorption by altering gene expression in osteoblasts.

Although the pharmacologic actions of CT have been studied extensively, there is a marked uncertainty about its role in mammalian physiology ${ }^{11,12}$. This is primarily based on the fact that patients with CT deficiency following thyroidectomy do not display the expected osteoporosis, and that bone mineral density was found decreased in individuals with medullary thyroid carcinoma (MTC) $)^{10,13}$. In addition, mice lacking Calca, the gene encoding CT and its related family member alpha CT-gene-related peptide ( $\alpha$ CGRP), unexpectedly displayed high bone mass, in contrast to mice specifically lacking aCGRP ${ }^{14-16}$. Importantly, although bone resorption was increased in aged Calca-deficient mice, there was a twofold higher bone formation rate at all ages analysed suggesting that the primary physiological function of $\mathrm{CT}$ is to limit osteoblast activity. These findings did not only challenge our understanding of CT as a bone-preserving hormone, they also raised several questions of key significance. In addition, they suggested that understanding the cellular and molecular mode of CT action would help to identify novel osteoanabolic treatment options.

To study the impact of CT on skeletal integrity, we generated a mouse model allowing cell type-specific deletion of two Calcr exons encoding the CT-binding site of the CTR. Here we show that CTR inactivation in all cell types or in osteoclasts specifically causes increased bone formation. The indirect influence of CT on bone formation is molecularly explained by a CTR-mediated inhibition of Spns2 expression, encoding a transporter for sphingosine 1-phosphate ( $\mathrm{S} 1 \mathrm{P})$, one of the previously identified molecules potentially coupling bone formation to bone resorption ${ }^{17,18}$. Likewise, S1P levels are increased in bones of CTR-deficient mice, and their skeletal phenotype is normalized by additional absence of $\mathrm{S}_{1} \mathrm{P}_{3}$, a $\mathrm{S} 1 \mathrm{P}$ receptor expressed by osteoblasts.

\section{Results}

Inactivation of the CTR specifically affects bone formation. To understand the mechanism of CT action on bone remodelling, we generated a floxed allele of the CTR by homologous recombination in embryonic stem cells. As it was reported that deletion of exons 6 and 7 from the Calcr gene causes embryonic lethality ${ }^{19}$, we constructed a targeting vector resulting in the insertion of loxP sites $5^{\prime}$ of exon 6 and $3^{\prime}$ of exon 7 , respectively (Supplementary Fig. 1a). After confirming homologous recombination by Southern blotting (Supplementary Fig. 1b), we removed the neomycin resistance cassette by Flp-mediated recombination and injected embryonic stem cells carrying one floxed Calcr allele into blastocysts to generate heterozygous mice. These were first mated with $C M V$-Cre transgenic mice ${ }^{20}$, leading to the generation of mice carrying a recombined Calcr allele, independent of Cre expression. The subsequent mating of $\mathrm{Calcr}^{+/}$- mice resulted in wild-type, heterozygous and Calcrdeficient animals, which were born at the expected Mendelian ratio (Supplementary Fig. 1c,d). Since this result did not confirm the embryonic lethality of Calcr-deficient mice observed by others $^{19}$, it was important to demonstrate loss of a functional CTR in our model. Immunohistochemistry confirmed the absence of the CTR protein in kidney and hypothalamus sections from $\mathrm{Calcr}^{-1}-$ mice (Fig. 1a), and binding assays employing iodinated CT demonstrated the lack of specific binding to cultured $\mathrm{Calcr}^{-1}$ osteoclasts (Fig. 1b). In addition, CT inhibited the resorptive activity of wild-type, but not of $\mathrm{Calcr}^{-/-}$osteoclasts, when these cells were cultured on dentin chips for 10 days (Fig. 1c).

After backcrossing the mutant allele into the $\mathrm{C} 57 \mathrm{Bl} / 6$ genetic background we analysed 12 weeks old wild-type and $\mathrm{Calcr}^{-/-}$ littermates for potential phenotypic abnormalities. Determination of blood parameters demonstrated no alterations in mineral homeostasis (Supplementary Table 1) and ruled out the existence of hepatic (Supplementary Table 2) and renal defects (Supplementary Table 3) in $\mathrm{Calcr}^{-1-}$ mice, which was confirmed by histology (Supplementary Fig. 1e). Importantly, $\mathrm{Calcr}^{-/-}$mice displayed higher circulating levels of alkaline phosphatase, suggesting increased bone formation as an underlying cause. Therefore, we went on to analyse the skeletal phenotype of $\mathrm{Calcr}^{-1-}$ mice using non-decalcified histology followed by static and dynamic histomorphometry. Here we observed an increased trabecular bone mass compared with wildtype littermates, which was solely explained by increased bone formation (Fig. 1d,e). Since osteoporosis is most common in aged individuals, we next assessed the skeletal phenotype of $\mathrm{Calcr}^{-9-}$ mice at 6,12 and 18 months of age. Compared with wild-type littermates $\mathrm{Calcr}^{-1-}$ mice displayed an increased trabecular bone mass together with an elevated bone formation rate at all ages analysed (Fig. 1f). In contrast, bone resorption was not increased in $\mathrm{Calcr}^{-} /-$mice, representing an unexpected finding as our previous analysis of aged CT-deficient mice revealed a high bone turnover phenotype with a more than twofold increase in bone resorption markers ${ }^{15}$.

To confirm this striking difference between the two models we applied $\mu \mathrm{CT}$-scanning and determined porosity of the femoral cortex (Fig. 2a) and calvarial bone (Fig. 2b) in 18-month-old mice. While only a moderate difference between wild-type and $\mathrm{Calcr}^{-1-}$ mice could be detected, we found severe cortical and calvarial porosity in CT-deficient $\mathrm{Calca}^{-/-}$mice that were maintained on the same genetic background. Since $\alpha \mathrm{CGRP}^{-/-}$ mice did not display this phenotype either, we hypothesized that the observed differences between Calcr ${ }^{-1}$ and Calca $^{-1-}$ mice are explained by the fact that the latter ones additionally lack procalcitonin (PCT), a well-established sepsis biomarker, which has been shown to interact with receptor complexes other than 


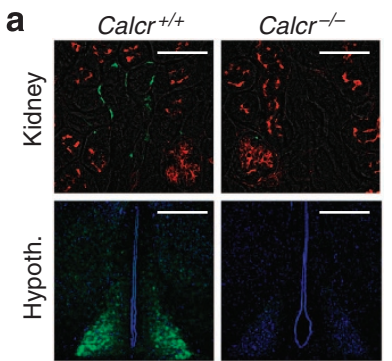

b

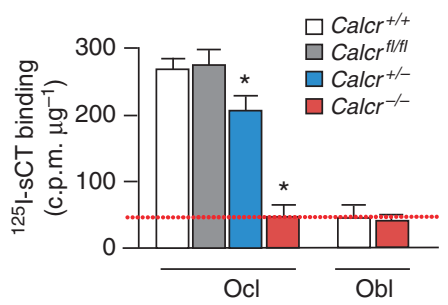

e
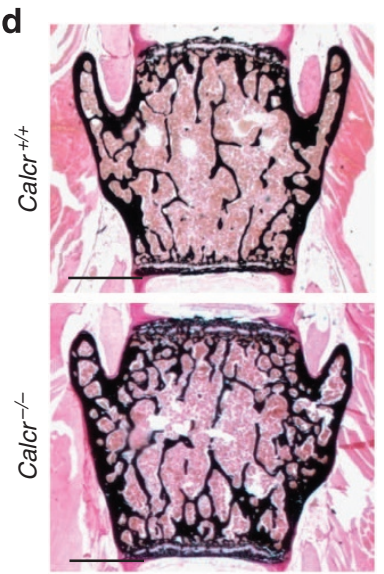

f
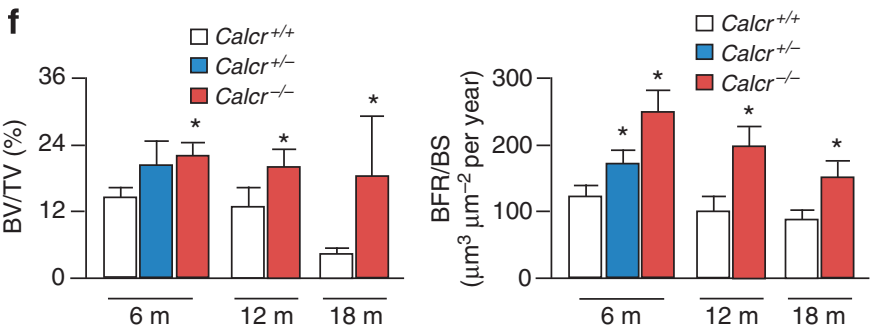
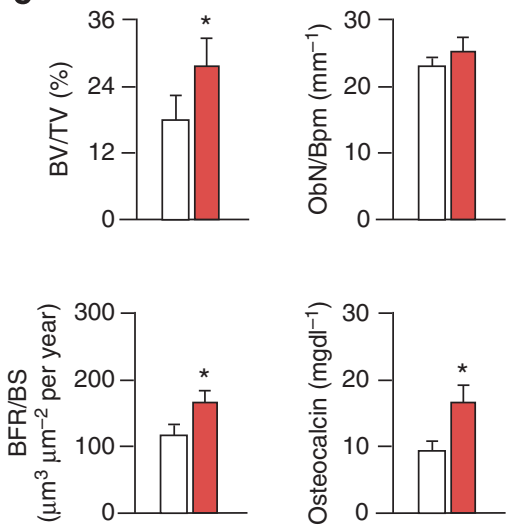

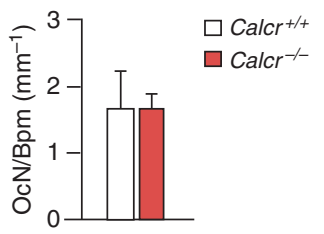

C
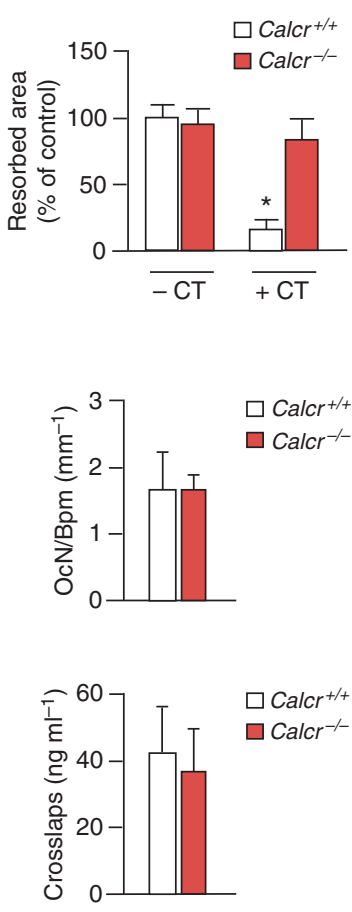

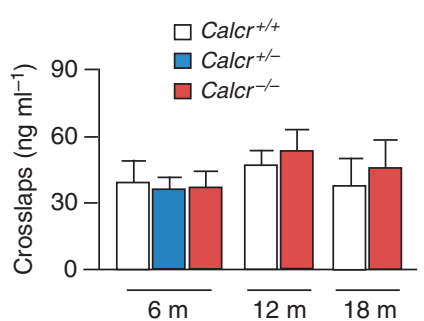

Figure 1 | Inactivation of the CTR specifically increases osteoblast function. (a) Immunohistochemistry for the CTR (stained in green) in kidney and hypothalamus (hypoth.) sections from wild-type and $\mathrm{Calcr}^{-/-}$mice. Scale bars, $50 \mu \mathrm{m}$ (top) and $200 \mu \mathrm{m}$ (bottom). (b) Binding of ${ }^{125} \mathrm{I}$-salmon CT to osteoclasts or osteoblasts of the indicated genotypes. The dotted red line represents nonspecific binding; $n=3$ cultures per group. ${ }^{\star} P<0.05$ versus wild-type. Data are representative of two independent experiments. (c) Quantification of dentin resorption by wild-type and Calcr- $-{ }^{-}$osteoclasts differentiated in the absence or presence of $C T ; n=3$ cultures per group. ${ }^{\star} P<0.05$ versus control. Data are representative of three independent experiments. (d) Von Kossa/van Gieson-staining of non-decalcified spine sections from 3-month-old female wild-type and Calcr ${ }^{-/-}$mice (scale bars, $1 \mathrm{~mm}$ ). (e) Histomorphometric quantification of the trabecular bone volume per tissue volume (BV/TV), the osteoblast number per bone perimeter $(\mathrm{ObN} / \mathrm{Bpm})$, the osteoclast number per bone perimeter (OcN/Bpm) and the bone formation rate per bone surface (BFR/BS). Concentrations of osteocalcin and collagen degradation products (crosslaps) were measured in serum; $n=6$ mice per group. ${ }^{\star} P<0.05$ versus wild-type. (f) Histomorphometric assessment of BV/TV, BFR/BS and serum crosslaps in 6-, 12- and 18-month-old female wild-type and Calcr ${ }^{-/-}$mice, and of 6-month-old Calcr ${ }^{+/-}$ mice; $n=6$ mice per group. ${ }^{\star} P<0.05$ versus wild-type. All error bars indicate s.d. $P$ values were assessed by two-tailed Student's $t$-test.

$\mathrm{CT}^{6,21}$. To address this possibility we injected lipopolysaccharide (LPS) onto the calvaria of 6-week-old wild-type, $\mathrm{Calcr}^{-1-}$, $\mathrm{Calca}^{-1-}$ and $\alpha \mathrm{CGRP}^{-1-}$ mice and applied $\mu \mathrm{CT}$ scanning 1 week thereafter (Fig. 2c). As expected, LPS treatment led to a significant increase in calvarial porosity in mice of all genotypes, yet its effect was significantly more pronounced in $\mathrm{Calca}^{-/-}$ mice. At the histological level these differences were explained by increased osteoclastogenesis (Fig. 2d), which led us to analyse the effect of PCT on osteoclast formation ex vivo. Here we found that the number of TRAP-positive multinucleated osteoclasts was significantly reduced by PCT, and most importantly the same was the case in $\mathrm{Calcr}^{-1}$ cultures (Fig. 2e). Collectively, these findings do not only suggest that PCT can affect bone mass in a CTR-independent manner, they also demonstrated that the major physiological function of the CTR is to limit the activity of osteoblasts.
The CTR in osteoclasts controls bone formation. To identify the relevant expression site mediating the inhibitory influence of the CTR on bone formation, we crossed Calcr fl/fl mice with transgenic mice expressing the Cre recombinase either in osteoblasts (Runx2-Cre), in the hypothalamus (CamK2a-Cre) or in the osteoclast lineage $(\text { Lysm-Cre })^{22-24}$. The specificity of the chosen approach was confirmed by genomic PCR amplifying the recombined allele from different tissues and bone cells (Supplementary Fig. 2a). In addition, we performed immunohistochemistry on hypothalamus sections (Fig. 3a) and binding assays with cultured osteoclasts (Fig. 3b), demonstrating that Calcr fl/fl mice carrying the CamK2a-Cre transgene lacked the CTR only in the hypothalamus, whereas binding of iodinated CT was decreased only in osteoclasts derived from Calcr fl/fl mice carrying the Lysm-Cre transgene. We next analysed the skeletal phenotype of the corresponding mice at 6 months 
a

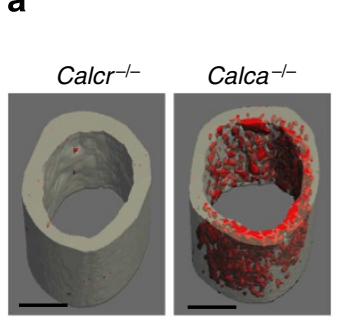

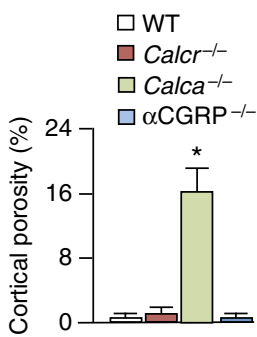

b

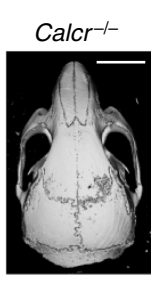

$\square$ WT

$\square \mathrm{Calcr}^{-1-}$

$\square \mathrm{Calca}^{-1-}$

$\mathrm{Calca}^{-1-}$
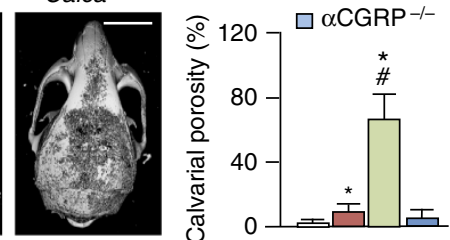
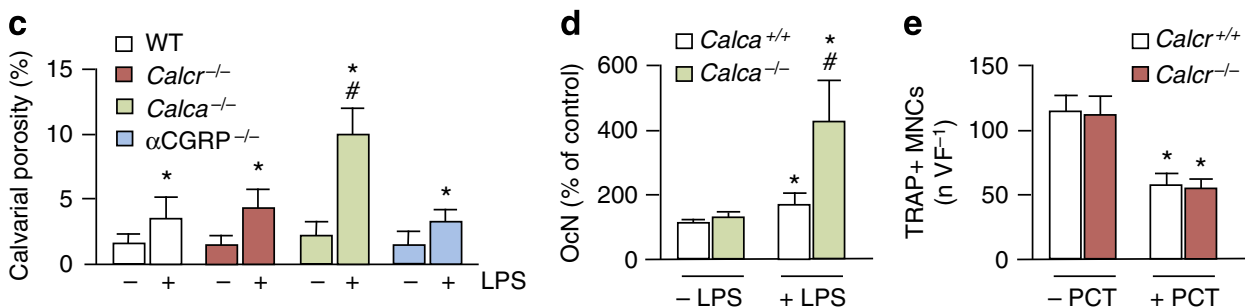

Figure 2 | Phenotypic differences between Calcr ${ }^{-/-}$and Calca ${ }^{-/-}$mice. (a) $\mu \mathrm{CT}$ scans of the femur from 18-month-old female Calcr ${ }^{-/-}$and $\mathrm{Calca}^{-/-}$mice. Scale bar, $500 \mu \mathrm{m}$. Cortical porosity for mice of the indicated genotypes is shown on the right; $n=5$. ${ }^{\star} P<0.05$ versus wild-type. (b) $\mu \mathrm{CT}$ scans of the calvaria from 18-month-old female $\mathrm{Calcr}^{-/-}$and Calca ${ }^{-/-}$mice. Scale bar, $1 \mathrm{~mm}$. Calvarial porosity for mice of the indicated genotypes is shown on the right; $n=5$. ${ }^{\star} P<0.05$ versus wild-type. (c) Calvarial porosity induced by local LPS injection in 6 weeks old wild-type, Calcr ${ }^{-/-}$, Calca ${ }^{-/-}$ and $\alpha$ CGRP $-/-$ mice; $n=5$. ${ }^{\star} P<0.05$ versus control. $\# P<0.05$ versus wild-type. (d) Osteoclast numbers in wild-type and Calca ${ }^{-/}-$mice with or without LPS treatment; $n=5$. ${ }^{\star} P<0.05$ versus control. \#P<0.05 versus wild-type. (e) TRAP-positive multinucleated cells (TRAP + MNCs) per visual field (VF) after differentiation of bone marrow cells with M-CSF and RANKL in the presence or absence of $10^{-8} \mathrm{M} P C T ; n=3 ;{ }^{\star} P<0.05$ versus non-treated wild-type. Data are representative of two independent experiments. All error bars indicate s.d. $P$ values were assessed by two-tailed Student's $t$-test.

a

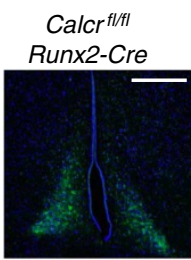

Calcr $r^{f / f t}$

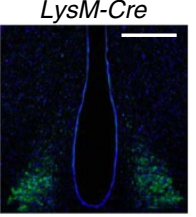

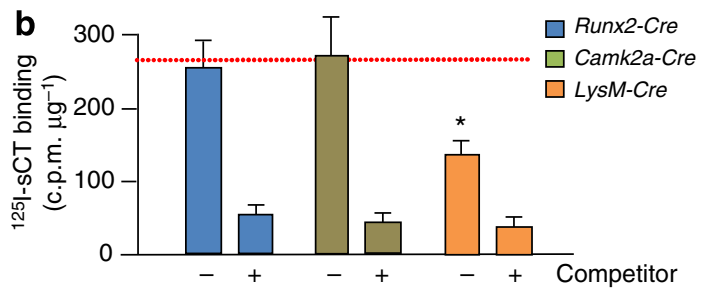

C

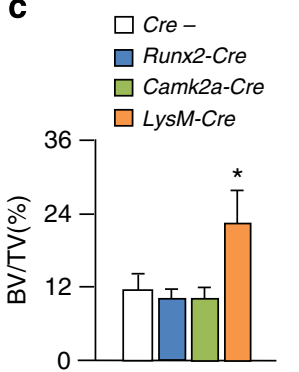

Calcr ${ }^{\text {fl/fI }}$ Camk2a-Cre

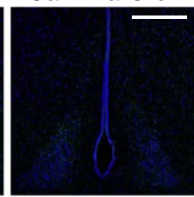

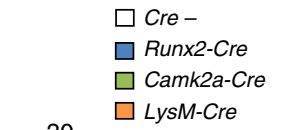
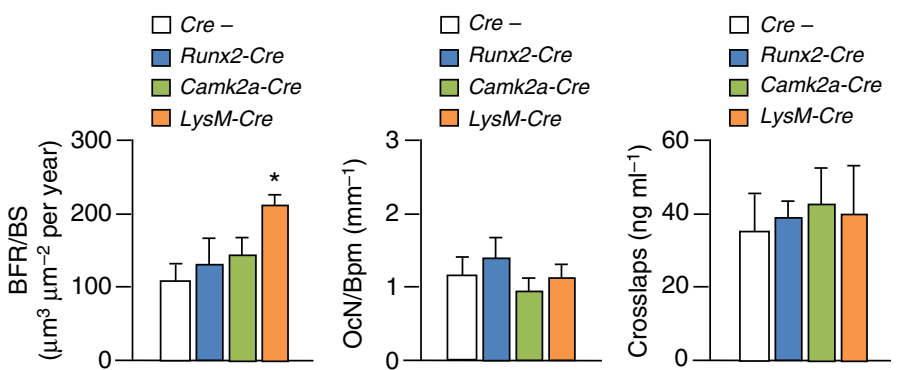

Figure 3 | Control of bone formation by the CTR in osteoclasts. (a) Immunohistochemistry for the presence of the CTR in hypothalamus sections. Scale bar, $200 \mu \mathrm{m}$. (b) Binding of ${ }^{125} \mathrm{I}-\mathrm{sCT}$ to differentiated osteoclasts derived from mice of the indicated genotypes. The dotted red line represents binding to Calcr ${ }^{f l / f l}$ osteoclasts; $n=3$ cultures per group. ${ }^{\star} P<0.05$ versus Calcr ${ }^{f l / f l}$ osteoclasts. Data are representative of two independent experiments.

(c) Quantification of BV/TV, ObN/Bpm, BFR/BS, OcN/Bpm and measurement of serum crosslaps in 12-month-old female mice of the genotypes indicated above; $n \geq 5$ mice per group. ${ }^{\star} P<0.05$ versus Calcr ${ }^{f / f l}$ mice. All error bars indicate s.d. $P$ values were assessed by two-tailed Student's $t$-test.

(Supplementary Fig. 2b) and 12 months (Fig. 3b) of age and found that the trabecular bone volume was increased only in $C_{\text {Calcr }}$ l/fl mice carrying the Lysm-Cre transgene. Consistent with the results from Calcr-1- mice, this phenotype was fully explained by increased bone formation, whereas bone resorption was not affected. These findings demonstrated that the inhibitory influence on bone formation is mediated by the CTR in osteoclasts, which led us to study the underlying molecular mechanisms by cell culture experiments.
CT negatively regulates S1P release from osteoclasts. We first confirmed the absence of an endogenous defect of CTR-deficient bone marrow cells in terms of osteoclast differentiation, as suggested by the previous data (Figs 1c and 2e). More specifically, we monitored expression of two key regulators of osteoclastogenesis, Nfatc1 and Fos, during the course of differentiation and found no difference between wild-type and $\mathrm{Calcr}^{-1}-$ cultures (Fig. 4a). Similar observations were made when the bone marrow cells were stimulated to differentiate into osteoblasts, where we did not 
a

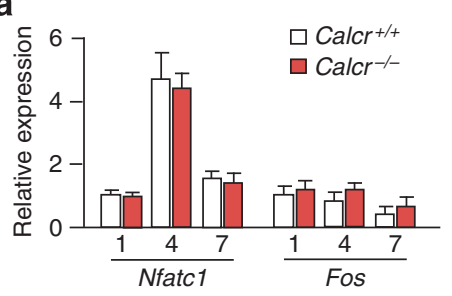

C

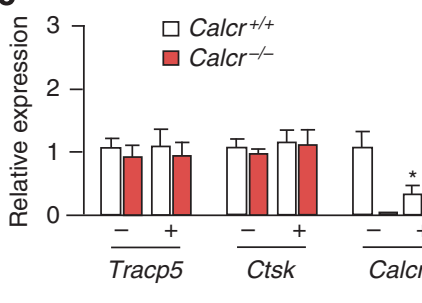

d

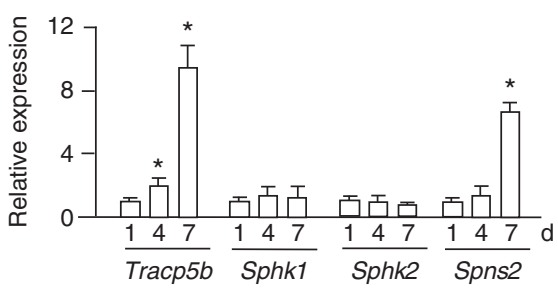

g

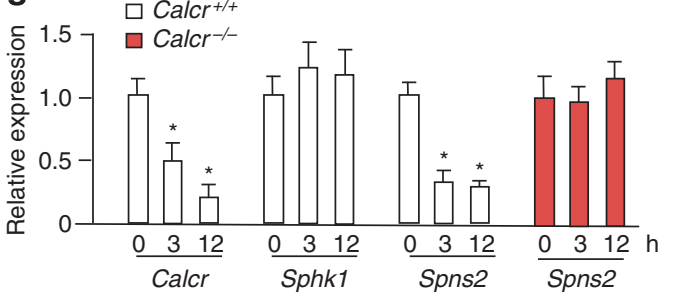

e
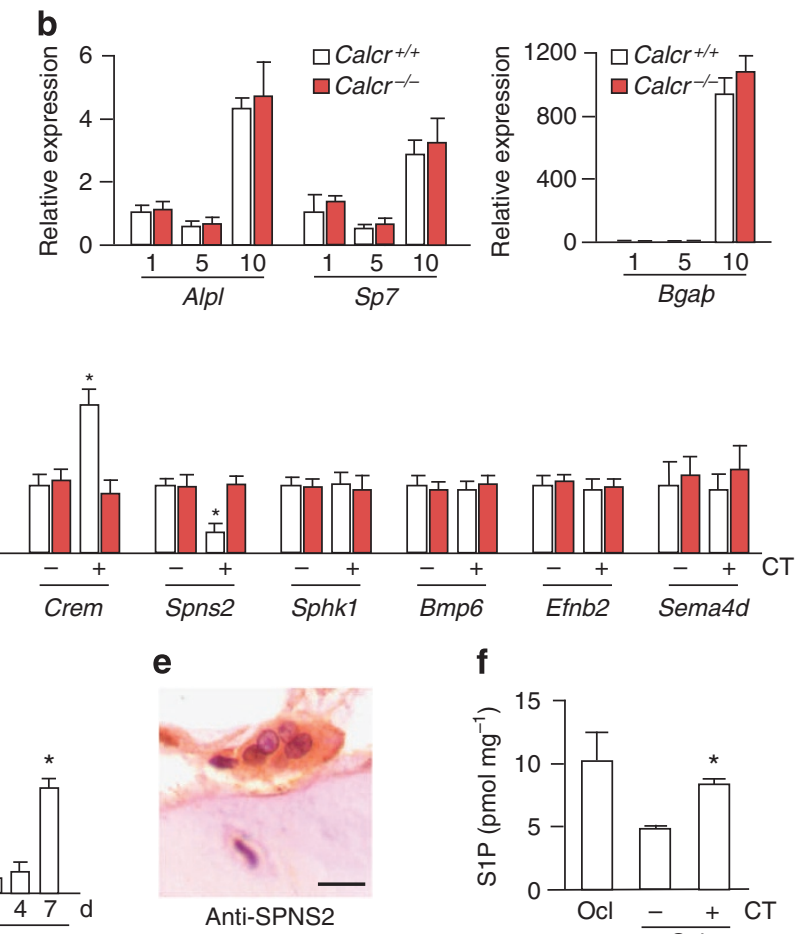

f
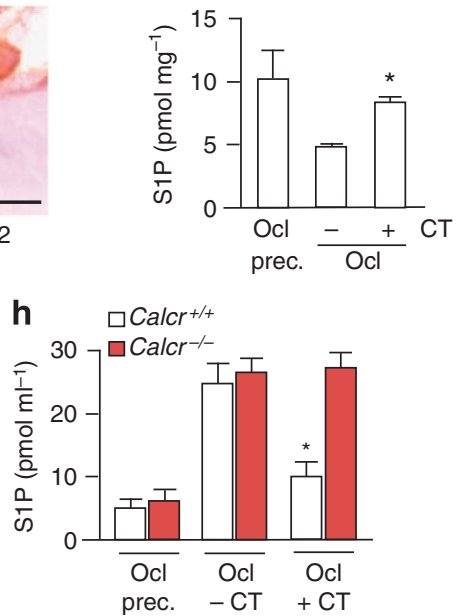

Figure 4 | CT inhibits S1P release from osteoclasts. (a) qRT-PCR expression analysis for the indicated genes during differentiation of wild-type and $\mathrm{Calcr}^{-/-}$bone marrow cells into osteoclasts; $n=3$ cultures per group. (b) qRT-PCR expression analysis for the indicated genes during differentiation of wild-type and Calcr $-/-$ bone marrow cells into osteoblasts; $n=3$ cultures per group. (c) Affymetrix signal intensities (relative to control) for selected genes in wild-type and $\mathrm{Calcr}^{-/-}$osteoclasts incubated in the absence or presence of $\mathrm{CT} ; n=3$ cultures per group. ${ }^{\star} P<0.05$ versus untreated $\mathrm{Calcr}+/+$ osteoclasts. (d) qRT-PCR expression analysis for the indicated genes during differentiation of wild-type osteoclasts; $n=4$ cultures per group. ${ }^{\star} P<0.05$ versus day 1. Data are representative of three independent experiments. (e) Immunohistochemistry for SPNS2 in an iliac crest biopsy section from a skeletal-intact donor. Scale bar, $20 \mu \mathrm{m}$. (f) Intracellular S1P concentrations in osteoclast precursors or differentiated wild-type osteoclasts incubated with or without $C T$ for $24 \mathrm{~h} ; n=3$ cultures per group. ${ }^{\star} P<0.05$ versus untreated osteoclasts. Data are representative of two independent experiments. (g) qRT-PCR expression analysis for Calcr, Sphk1 and Spns2 in wild-type and Calcr ${ }^{-/-}$osteoclasts incubated with CT for the indicated time; $n=4$ cultures per group. ${ }^{\star} P<0.05$ versus control. Data are representative of three independent experiments. (h) Extracellular S1P concentrations in conditioned medium of wild-type and $\mathrm{Calcr}^{-/-}$osteoclast precursors (Ocl prec.) or differentiated osteoclasts incubated with or without $\mathrm{CT}$ for $24 \mathrm{~h}$; $n=3$ cultures per group. ${ }^{\star} P<0.05$ versus untreated osteoclasts. Data are representative of three independent experiments. All error bars indicate s.d. $P$ values were assessed by two-tailed Student's t-test.

observe differential expression of osteogenic markers, such as Alpl, Sp7 and Bglap (Fig. 4b). We next isolated RNA from wildtype and Calcr ${ }^{-I}$ osteoclasts treated with CT for $6 \mathrm{~h}$ to perform genome-wide expression analysis. This allowed us to identify at least 29 genes regulated by CT specifically in wild-type osteoclasts (Supplementary Fig. 3a). Our analysis revealed that the expression of well-established osteoclast markers, such as Tracp5 and Ctsk, was not affected by CT administration, while the expression of Calcr and Crem, the two previously known CT target genes in osteoclasts $^{25,26}$, was regulated as expected (Fig. 4c). Most importantly, we identified Spns 2 as a gene negatively regulated by CT specifically in wild-type osteoclasts. Spns 2 encodes a transmembrane protein involved in the secretion of $\mathrm{S}_{1} \mathrm{P}^{27,28}$, which has been shown to function as an osteoanabolic factor coupling bone formation to resorption in vitro ${ }^{17,18,29}$. Since this raised the possibility that the CTR-dependent control of bone formation is mediated by reducing S1P release from osteoclasts, and since other genes with a putative role in osteoclast to osteoblast communication (Sphk1,Bmp6, Efnb2 and Sema4d) were not differentially expressed, we focused on Spns2 as a relevant downstream target of CT in the control of bone formation.

Consistent with the suspected role of Spns2 in osteoclast to osteoblast communication, we observed that its expression increased during osteoclastogenesis of wild-type cells, in contrast to Sphk1 and Sphk2, the two genes required for intracellular S1P production (Fig. 4d). Likewise, immunohistochemistry on human bone sections revealed that SPNS2 was readily detectable in multinucleated osteoclasts at the bone surface (Fig. 4e). Consistent with the higher expression of Spns2 in differentiated 
osteoclasts, we found that intracellular S1P levels declined during the course of osteoclastogenesis and that CT administration significantly increased them (Fig. 4f). Likewise, quantitative PCR with reverse transcription (qRT-PCR) confirmed that Spns2 expression is negatively regulated by short-term administration of CT to wild-type osteoclasts, but not to $\mathrm{Calcr}^{-1-}$ osteoclasts (Fig. 4g). As it was previously demonstrated that protein kinase A (PKA), protein kinase $\mathrm{C}$ (PKC) and phospholipase $\mathrm{C}$ (PLC) are the major intracellular effectors of CTR-dependent signalling $\mathrm{s}^{25,30,31}$, we investigated which of these pathways is involved in the transcriptional regulation of Spns2 by CT. Here we found that the inhibition of Spns2 expression by CT was abrogated in the presence of the PLC inhibitor U-73122, but not by a PKC or PKA inhibitor, indicating an involvement of the PLC-signalling pathway (Supplementary Fig. 3b). In addition, we found that Spns2 protein levels were markedly decreased after $9 \mathrm{~h}$ of CT administration (Supplementary Fig. 3c), thereby supporting our conclusion that Spns2 is a direct target of CT in osteoclasts. To demonstrate the functional consequence of this regulation, we determined S1P levels in the medium of wild-type and Calcr ${ }^{-1-}$ osteoclast cultures. In both wild-type and $\mathrm{Calcr}^{-1-}$ osteoclast cultures extracellular S1P levels increased upon differentiation, whereas CT administration for $24 \mathrm{~h}$ resulted in a significant reduction only in wild-type cultures (Fig. 4h). Taken together, these results suggested that the CTR controls bone formation by reducing S1P release from osteoclasts, which led us to address the question as to which of the five known S1P receptors ${ }^{32,33}$ is involved in the regulation of bone formation downstream of CT.

Control of bone formation by $\mathbf{S 1 P}_{3}$. We next determined the expression of S1pr1-5 in different tissues as well as in primary bone cells by RT-PCR (Supplementary Fig. 4a) and during the course of their differentiation by qRT-PCR (Fig. 5a). Here we found that S1pr1 and S1pr3 were differentially expressed during osteoblastogenesis, both increasing at early stages of differentiation. Since S1prl-deficient mice die in utero ${ }^{34}$, in contrast to S1pr3-deficient mice, which do not display obvious abnormalities ${ }^{35}$, we first analysed the skeletal phenotype of S1pr3-deficient mice. Our histomorphometric analysis revealed that bone remodelling parameters did not differ between wildtype and S1pr3-deficient mice at 3 months of age. In contrast, 8-month-old S1pr3-deficient mice displayed osteopenia and reduced bone formation, while bone resorption parameters were unaffected (Fig. 5b). We additionally generated mice lacking S1pr1 specifically in osteoblasts, but here we failed to detect alterations in bone mass or bone remodelling parameters at both ages (Supplementary Fig. 4b-d). These findings identified $\mathrm{S}_{\mathrm{P}} \mathrm{P}_{3}$, encoded by the S1pr3 gene, as a candidate receptor controlling bone formation in response to S1P, which led us to utilize the S1pr3-deficient mouse model for additional experiments.

Here we first cultured primary calvarial osteoblasts from wildtype and S1pr3 $3^{-1-}$ mice in the presence of conditioned medium derived from osteoclast progenitors or from osteoclasts terminally differentiated with or without CT. After 10 days of culture we quantified matrix mineralization and found that only conditioned medium of osteoclasts cultured without CT caused on osteoanabolic effect in wild-type cultures, whereas $S 1 p r 3^{-1-}$ cells did not respond (Fig. 5c). Likewise, S1P significantly increased matrix mineralization in wild-type, but not in S1pr3 $3^{-1-}$ bone marrowderived osteoblast cultures (Fig. 5d). Moreover, S1P treatment resulted in a rapid phosphorylation Erk1/2 in primary calvarial osteoblasts from wild-type, but not from S1pr3 $3^{-1-}$ mice (Fig. 5e, Supplementary Fig. 5). To analyse immediate effects on gene expression we treated wild-type and $S 1 \mathrm{pr}^{-1-}$ bone marrow cells at day 10 of osteogenic differentiation with S1P for $6 \mathrm{~h}$ and subsequently performed qRT-PCR for selected genes (Fig. 6a). Similar to the effect of CT on Calcr expression in osteoclasts, S1P negatively regulated S1pr3 expression in wild-type cultures. Importantly, short-term S1P administration caused an $\mathrm{S}_{1} \mathrm{P}_{3^{-}}$ dependent increase in the expression of Colla1, Ibsp, and Smpd3, all of which are involved in bone matrix production by osteoblasts $^{36-38}$, and addition of the MEK1 inhibitor PD98059 blunted the stimulatory effect of S1P on Colla1 expression (Fig. 6b). Taken together, these results suggested that $\mathrm{S} \mathrm{P}_{3}$ is one relevant receptor acting downstream of $\mathrm{CT}$ to control bone formation.

Since S1P has been shown to induce expression of the proosteoclastogenic cytokine Rankl in osteoblasts, we additionally performed qRT-PCR to assess transcription of the genes encoding Rankl (Tnfsf11) or its decoy receptor Opg (Tnfrsf11b). While Tnfsf11 expression was induced by S1P stimulation of wild-type and S1pr3-1- bone marrow cells, Tnfrsf11b was not affected (Fig. 6c). These results raised the question as to why the suspected increase of S1P release in $\mathrm{Calcr}^{-1-}$ mice does not amplify osteoclastogenesis. In an attempt to address this question, we took advantage of Sgpl1-1- mice, lacking S1P-lyase, an enzyme required for S1P degradation ${ }^{39}$. Due to high extracellular S1P levels, Sgpl1 ${ }^{-1-}$ mice display various abnormalities and reduced life span (29 days in average). Remarkably, however, their bone mass was progressively increasing and approximately doubled compared with wild-type littermates in all animals reaching the age of 6 weeks (Fig. 6d,e). Of note, TRAP activity staining combined with cellular histomorphometry demonstrated increased osteoclastogenesis in Sgpl1 ${ }^{-1-}$ mice (Fig. 6f). Importantly, these osteoclasts were functionally active, as the serum crosslaps concentrations were significantly increased, and the same was the case for PICP, a biomarker of bone formation (Fig. 6g). These findings fully confirm the osteoanabolic function of S1P in vivo and suggest that an S1P-driven high bone turnover is only detectable when the extracellular S1P level exceed a certain threshold.

S1pr3-deficiency abrogates osteoanabolic influences. To analyse if S1P is responsible for the high bone mass phenotype of Calcr $^{-1-}$ mice, we determined S1P levels in serum and bones of 6-month-old wild-type and $\mathrm{Calcr}^{-1-}$ littermates. Here we did not identify differences in circulating S1P levels, yet S1P concentrations were significantly increased in femur and spine extracts of $\mathrm{Calcr}^{-} \mathrm{P}_{-}$mice, and the same was the case in $\mathrm{Calca}^{-1-}$ mice (Fig. 7a). We next generated mice lacking both, the CTR and $\mathrm{S}_{1} \mathrm{P}_{3}$, and compared their skeletal phenotype to wild-type, Calcr ${ }^{-1-}$ and $\mathrm{S1pr}^{-I-}$ controls at 4 months of age. Here we observed the expected increase of trabecular bone mass and bone formation in Calcr ${ }^{-1-}$ mice, yet this phenotype was not present in $\mathrm{Calcr}^{-1-}$ mice additionally lacking of $\mathrm{S}_{3} \mathrm{P}_{3}$ (Fig. 7b). Since it was described that daily injection of the nonselective S1P receptor agonist FTY720 protects against ovariectomy-induced bone loss in wild-type mice ${ }^{40}$, we further investigated whether this effect is attributable to an $\mathrm{S}_{1} \mathrm{P}_{3}$ dependent increase in bone formation. Therefore, we analysed the skeletal phenotype of wild-type and S1pr3 ${ }^{-I-}$ mice that received daily vehicle or FTY720 injections for 4 weeks, starting at the age of 3 months. FTY720 administration at a dose of $6 \mathrm{mg} \mathrm{kg}^{-1}$ resulted in a significantly increased trabecular bone volume in wild-type mice, whereas S1pr3 ${ }^{-1-}$ mice did not respond (Fig. 7c). Most importantly, although osteoclast parameters were not different in the six groups of mice, the bone formation rate was significantly increased by FTY720 administration in wild-type, but not S1pr3 $3^{-1-}$ mice. 
a
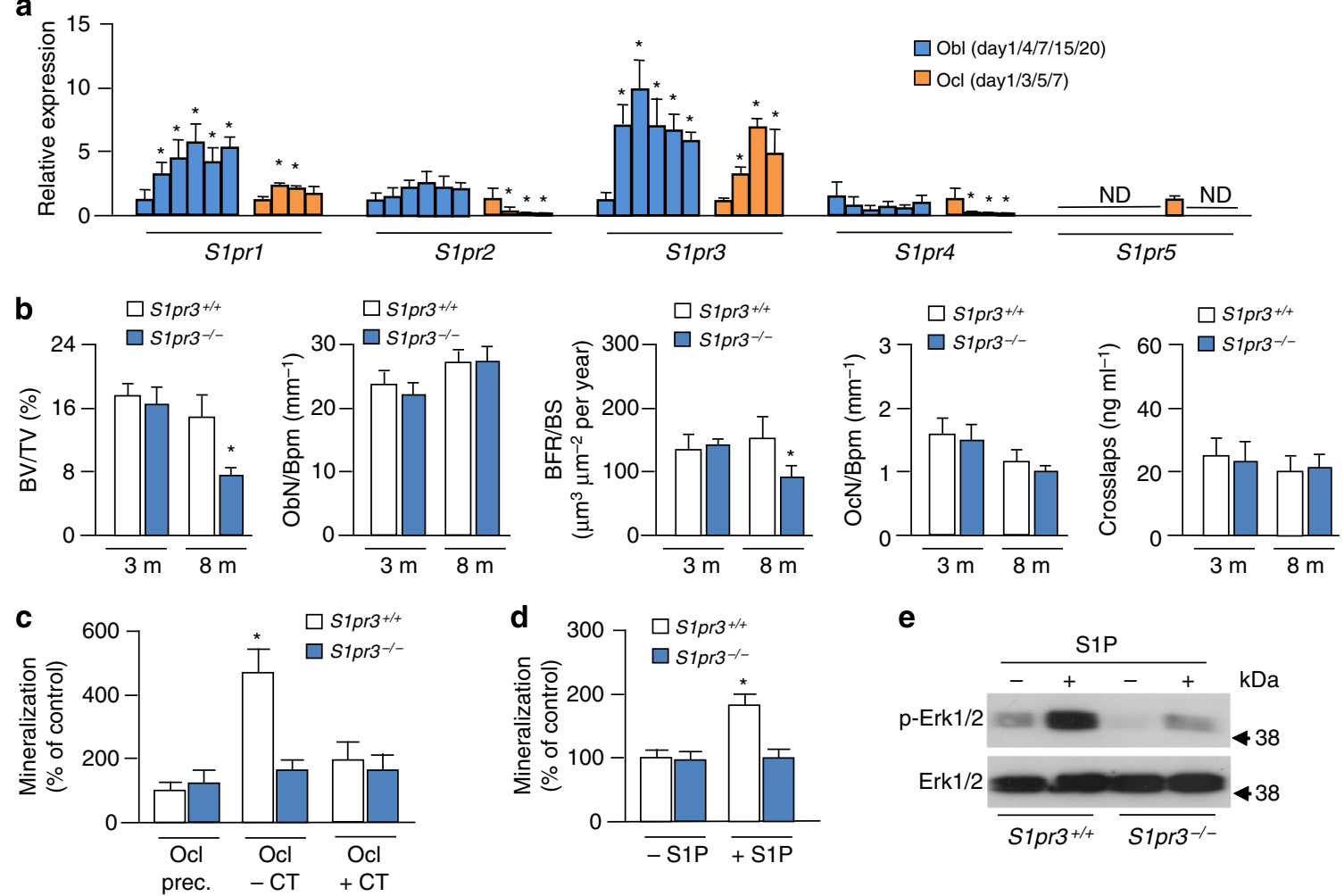

Figure 5 I S1P $_{3}$ controls bone formation. (a) qRT-PCR expression analysis for the indicated genes in primary osteoblasts (Obl) or osteoclasts (Ocl) at different days of differentiation (ND, non-detectable). Data are representative of two independent experiments. (b) Quantification of BV/TV, ObN/Bpm, $\mathrm{BFR} / \mathrm{BS}, \mathrm{OcN} / \mathrm{Bpm}$ and measurement of serum crosslaps in 3- and 8-month-old female wild-type and S1pr3-/- mice; $n=5$ mice per group. ${ }^{\star} P<0.05$ versus wild-type. (c) Quantification of mineralization in wild-type and S1pr3-/- primary osteoblasts differentiated for 10 days in the presence of conditioned medium from wild-type osteoclast precursors (Ocl prec.; control) or differentiated osteoclasts being incubated in the absence or presence of $\mathrm{CT} ; n=3$ cultures per group. ${ }^{\star} P<0.05$ versus control. Data are representative of two independent experiments. (d) Quantification of mineralization in wildtype and S1pr3 ${ }^{-/-}$primary osteoblasts differentiated for 10 days in the absence or presence of S1P; $n=3$ cultures per group. ${ }^{\star} P<0.05$ versus control. Data are representative of two independent experiments. (e) Western Blot monitoring Erk1/2 phosphorylation in wild-type and S1pr3-/- primary osteoblasts with or without S1P treatment for $15 \mathrm{~min}$ (uncropped blots are presented in Supplementary Fig. 5). All error bars indicate s.d. $P$ values were assessed by two-tailed Student's t-test.

Since these results suggested that $\mathrm{S}_{1} \mathrm{P}_{3}$ might be an attractive target for osteoanabolic therapy, we further assessed whether its presence on osteoblasts is also detectable in human bone sections. Using immunohistochemistry we found that $\mathrm{S}_{1} \mathrm{P}_{3}$ was detectable not only in spine sections from wild-type mice, but also in iliac crest biopsy sections from an individual with Paget's disease of bone, a condition characterized by a local increase of bone remodelling (Fig. 7d). Taken together, our findings provide a cellular and molecular explanation for the role of CT in mammalian physiology and identify a physiologically relevant coupling mechanism in bone remodelling that can be targeted for osteoanabolic treatment of bone loss disorders (Fig. 7e).

\section{Discussion}

Our results have identified a cellular and molecular explanation for the previously ambiguous role of CT in mammalian physiology. They demonstrate that bone formation is controlled by the CTR in osteoclasts, where CT reduces S1P secretion by inhibiting Spns2 expression. In turn, the high bone mass phenotype in mice lacking the CTR is the consequence of locally increased S1P levels, which is best underscored by the phenotypic rescue through additional deletion of $\mathrm{S}_{3} \mathrm{P}_{3}$. These findings are important and clinically relevant for several reasons. First, they demonstrate that the primary physiological function of mammalian CT in bone remodelling is entirely different from its pharmacologic action, similar to PTH, a hormone physiologically activating osteoclastogenesis, but pharmacologically increasing bone formation ${ }^{41}$. Second, they fully support the previously suggested role of S1P as a factor coupling bone formation to bone resorption, which was based on in vitro- and ex vivoevidence ${ }^{17,18,29}$. Third, they have identified two promising target molecules for an osteoanabolic treatment of bone loss disorders, and it is important to state that the CTR and $\mathrm{S}_{1} \mathrm{P}_{3}$ are both serpentine receptors, representing the major class of target proteins for drug development ${ }^{32,33,42}$.

Since CT was initially identified as a potent inhibitor of bone resorption at high pharmacological doses, it has long been considered as surprising that thyroidectomy does not cause osteopenia, and that bone mineral density is even decreased in individuals with $\mathrm{MTC}^{12}$. During the course of our study we identified three patients with CT deficiency due to thyroiditis, and three patients with high CT serum levels due to MTC (Supplementary Table 4). Dual-energy X-ray absorptiometry (DEXA) revealed high bone mineral density in patients with CT deficiency, whereas the opposite was observed in patients with CT excess (Supplementary Fig. 6a,b). We additionally recruited 17 previously thyroidectomized individuals (Supplementary Table 5) to perform DEXA analyses, where we observed a significant positive correlation between bone mineral density and time after thyroidectomy (Supplementary Fig. 6c). These findings, despite several limitations of our analysis, are principally in agreement 
a

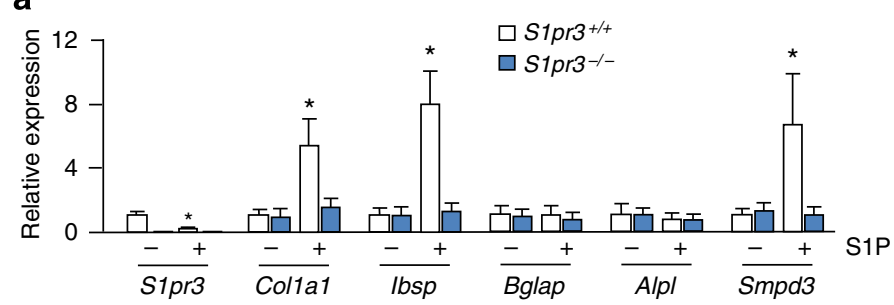

C

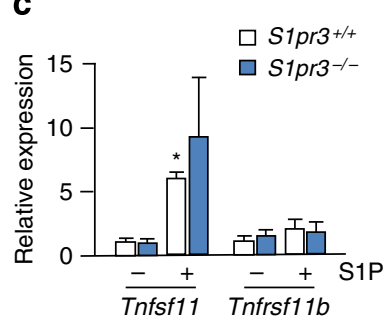

$\mathbf{f}$

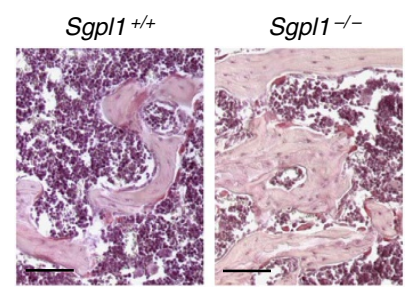

d $S g p / 1^{+/+}$

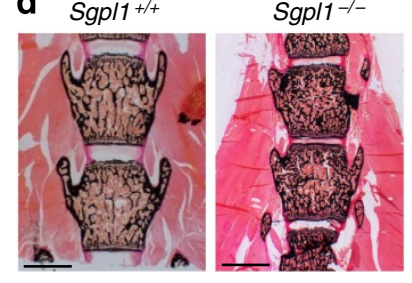

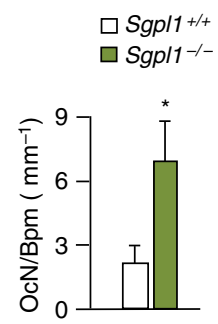

b
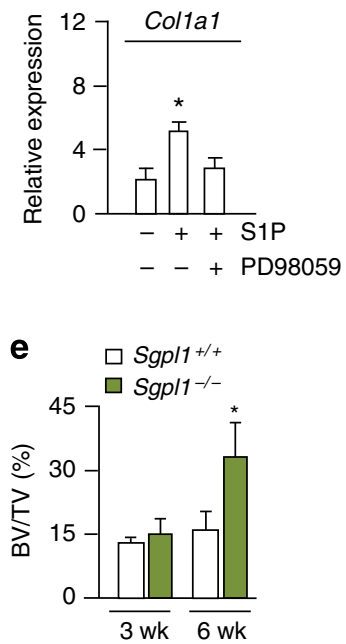

g

$\square$ Sgpl $1^{+/+}$

$\square$ Sgpl1 +/+
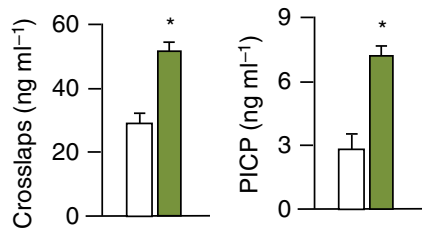

Figure 6 | S1P affects gene expression in osteoblasts and accelerates bone turnover. (a) qRT-PCR expression analysis for the indicated genes in wild-type and S1pr3 ${ }^{-/-}$osteoblasts incubated in the absence or presence of S1P for $6 \mathrm{~h} ; n=3$ cultures per group. ${ }^{\star} P<0.05$ versus control. Data are representative of two independent experiments. (b) qRT-PCR expression analysis for Col1a1 in wild-type osteoblasts stimulated with S1P in the absence or presence of PD98059 as indicted; $n=3$ cultures per group. ${ }^{\star} P<0.05$ versus control. (c) qRT-PCR expression analysis for the indicated genes in wild-type and S1pr $3^{-/-}$osteoblasts incubated in the absence or presence of S1P for $6 \mathrm{~h} ; n=3$ cultures per group. ${ }^{\star} P<0.05$ versus control. Data are representative of two independent experiments. (d) Von Kossa/van Gieson-staining of non-decalcified spine sections from 6 weeks old wild-type and Sgp/1 ${ }^{-/-}$ mice. Scale bar, $500 \mu \mathrm{m}$. (e) Quantification of BV/TV in 3 and 6 weeks old female wild-type and Sgp/1 ${ }^{-/-}$mice; $n \geq 3$ mice per group. ${ }^{\star} P<0.05$ versus wild-type. (f) TRAP activity staining reveals a high number of multinucleated osteoclasts (stained in red) in decalcified spine sections from 6 weeks old Sgp/1 ${ }^{-/-}$mice. Scale bar, $50 \mu \mathrm{m}$. Quantification of OcN/Bpm is shown on the right; $n=3$ mice per group. ${ }^{*} P<0.05$ versus wild-type. (g) Serum crosslaps and PICP concentrations in 6 weeks old female wild-type and Sgp $11^{-/-}$mice; $n=3$ mice per group. ${ }^{\star} P<0.05$ versus wild-type. All error bars indicate s.d. $P$ values were assessed by two-tailed Student's $t$-test.

with the data obtained in mouse models, and they provide further evidence for a physiological role of mammalian CT as an inhibitor of bone formation. At that point it is again important to state that many conclusions regarding the functions of CT are based on experiments performed with salmon CT. This protein shares only $50 \%$ sequence homology to human $\mathrm{CT}$, which may not only translate into different binding characteristics to the CTR, but also in differential effects on bone remodelling. Therefore, our findings do not at all question the antiresorptive effect of pharmacological salmon CT administration, they only show that mammalian CT has another influence under physiological conditions.

We and others have previously shown that mice lacking CT or one allele of the CTR display increased bone formation ${ }^{14,15,19}$. Albeit these data already suggested that the primary physiological function of CT is different from its pharmacologic effect, there were still several remaining questions ${ }^{43}$. In fact, while the homozygous deletion of exons 6 and 7 of the Calcr gene, which encode the CTR binding site, has been reported to cause embryonic lethality ${ }^{19}$, a $C M V$-Cre-mediated deletion of the $3^{\prime}$-Calcr exons 13 and 14 did not result in embryonic lethality or obvious alterations of bone remodelling, which was potentially explained by insufficient recombination ${ }^{44}$. On the basis of these inconsistencies, it was important that we could demonstrate loss of CTR expression and function in our mouse model by several means, and that we could identify increased bone formation as their only phenotype. Although we do not have a sufficient explanation for the previously described lethality of mice lacking the Calcr exons 6 and 7, it is important to state that one difference between the two targeting strategies is the absence or presence of the $\mathrm{Neo}^{\mathrm{R}}$ cassette. In fact, since there are several reports demonstrating a phenotypic influence of such an insertion ${ }^{45-47}$, we have applied Flp-mediated recombination to remove the $\mathrm{Neo}^{\mathrm{R}}$ cassette before our phenotypic analysis. Our data clearly demonstrated that the major physiological function of the murine CTR is to limit bone formation, which led us to address the remaining questions about the underlying cellular and molecular mechanism.

Since the CTR is known to be present on hypothalamic neurons and differentiated osteoclasts, and since recent evidence has suggested that it might also be expressed by terminally differentiated osteoblasts ${ }^{48}$, we specifically deleted the Calcr exons 6 and 7 in the hypothalamus, in osteoblasts or in cells of the osteoclast lineage to uncover the cellular and molecular mechanism explaining the inhibitory effect of CT on bone formation. The subsequent skeletal analysis demonstrated that the presence of the CTR in osteoclasts is required for regulating the activity of osteoblasts, thereby contradicting the hypothesis 
$\square \mathrm{Calcr}^{+/+}$

$\square \mathrm{Calcr}^{-/-}$
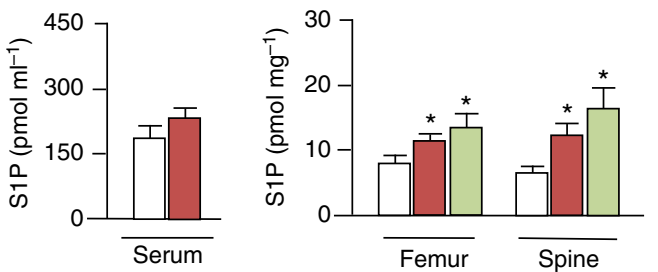

C

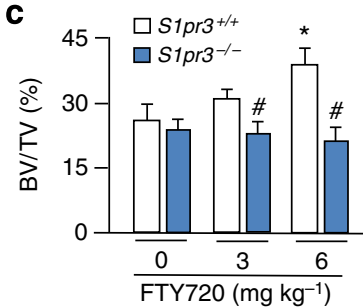

d

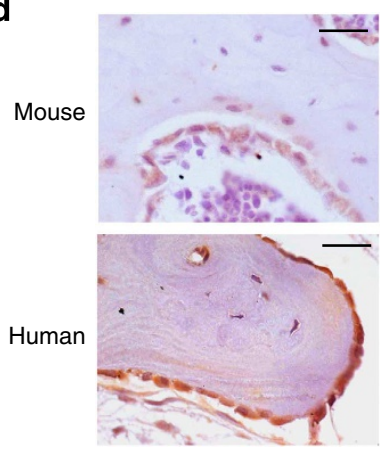

e b

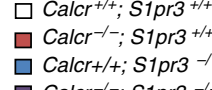

$\mathrm{Calcr}^{-1-} \cdot \mathrm{Sipr}^{-1-}$

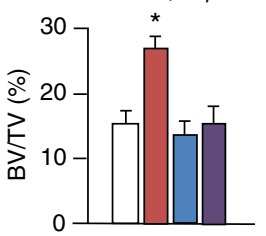

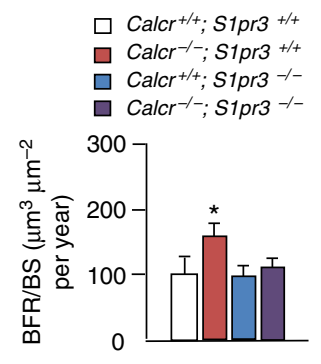
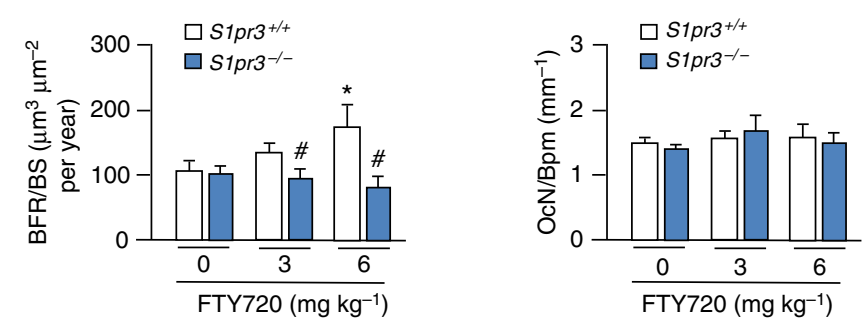

Osteoclast

Osteoblasts

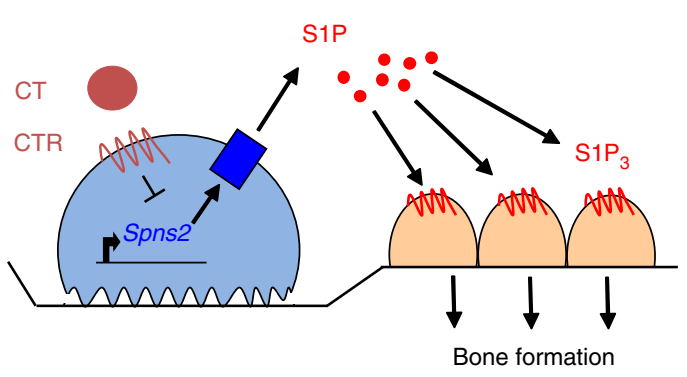

Figure 7 | S1pr3-deficiency abrogates the osteoanabolic effect caused by CTR deficiency or FTY720. (a) S1P levels in serum and bones from 6-monthold female wild-type and $\mathrm{Calcr}^{-/-}$mice, and in bones from 6 -month-old Calca ${ }^{-/-}$mice; $n=5$ mice per group. ${ }^{\star} P<0.05$ versus wild-type controls. (b) Quantification of BV/TV and BFR/BS in 4-month-old female mice of the indicated genotypes; $n=5$ mice per group. ${ }^{*} P<0.05$ versus wild-type. (c) Quantification of BV/TV, BFR/BS and OcN/Bpm in 4-month-old female mice of the indicated genotypes receiving daily injections of vehicle or FYT720 at two different doses; $n=6$ mice per group. ${ }^{\star} P<0.05$ versus vehicle-treated $S 1 p r 3^{+/+}$mice. ${ }^{\#} P<0.05$ versus wild-type. (d) Immunohistochemistry for $\mathrm{S}_{3} \mathrm{P}_{3}$ in spine sections from wild-type mice (top) and in iliac crest biopsy sections of an individual with Paget's disease of bone (bottom). Scale bars, $25 \mu \mathrm{m}$ (top) and $50 \mu \mathrm{m}$ (bottom). (e) Schematic representation of the proposed function of the CTR in bone formation. All error bars indicate s.d. P values were assessed by two-tailed Student's $t$-test.

raised by us and others that CT inhibits bone formation through a hypothalamic relay ${ }^{10,19,43}$. Instead, our data demonstrate that $\mathrm{CT}$ and the CTR are involved in the molecular crosstalk between osteoclasts and osteoblasts. Clinically, there are several bone remodelling disorders where increased bone formation is triggered by excessive osteoclastogenesis, the most evident example being Paget's disease of bone ${ }^{49-52}$. Molecularly, several tissue culture experiments together with genetic evidence from mouse models have led to the identification of candidate molecules mediating this function, such as EphrinB2, BMP6, Sema4d or $\mathrm{S} 1 \mathrm{P}^{17,18,53,54}$.

In the light of this knowledge, we performed genome-wide expression analysis with the aim to identify a coupling factorencoding gene being regulated in a CTR-dependent manner. Here we did not observe an immediate transcriptional regulation of theses genes by CT, and the same was the case for Sphk1. In the context of S1P this latter finding is particularly important, as differential Sphk1 expression during osteoclastogenesis was the first experimental evidence for S1P as a relevant coupling factor in bone remodelling ${ }^{18}$. Instead, we observed a CTR-dependent negative regulation of Spns2 expression, which was potentially important, since this gene encodes a transmembrane protein required for S1P release from various cell types ${ }^{27,28,55}$. Our qRTPCR expression analysis revealed that Spns 2 expression increases during osteoclastogenesis, similar to extracellular S1P levels. Likewise, short-term administration of CT to wild-type, but not to $\mathrm{Calcr}^{-1}$ - osteoclasts, caused a significant reduction of both, Spns2 expression and extracellular S1P accumulation. Consistent with these in vitro experiments, $\mathrm{Calcr}^{-1-}$ mice displayed increased S1P levels in bone extracts, and their skeletal phenotype was normalized by the additional absence of $\mathrm{S}_{3} \mathrm{P}_{3}$. Taken together, these results demonstrate that the indirect action of CT on bone formation is explained by locally increased S1P concentrations, thereby supporting the concept that $\mathrm{S} 1 \mathrm{P}$ receptors serve an osteoanabolic function.

Although we cannot fully rule out a contribution of additional $\mathrm{S} 1 \mathrm{P}$ receptors, our results demonstrate that $\mathrm{S}_{\mathrm{P}} \mathrm{P}_{3}$ is one relevant receptor required to promote bone formation in response to S1P. While the lack of a bone remodelling phenotype in 3-month-old S1pr3-deficient mice is potentially explained by functional redundancy, most likely involving S1pr1 based on its differential expression in osteoblasts, it was evident that S1pr3-deficiency blunted the effects of S1P in vitro, but also in vivo in the context of CTR deficiency. From a therapeutic perspective, the finding 
that FTY720 causes an $\mathrm{S}_{1} \mathrm{P}_{3}$-dependent osteoanabolic effect is of particular interest, as this nonselective S1P receptor agonist has already been approved for the treatment of individuals with multiple sclerosis ${ }^{56,57}$. In a previous study, FTY720 administration $\left(3 \mathrm{mg} \mathrm{kg}^{-1}\right)$ was found to protect against ovariectomy-induced bone loss due to a negative effect on osteoclast attachment to the bone matrix ${ }^{40}$. Although we principally used the same strategy of FTY720 administration, it is important to clarify the three relevant modifications compared with this former experiment. First, since we only observed a trend, and not a significant increase of the trabecular bone volume by daily injection of FTY720 at a dose of $3 \mathrm{mg} \mathrm{kg}^{-1}$, we repeated the experiment with a higher dose $\left(6 \mathrm{mgkg}^{-1}\right)$ to demonstrate an osteoanabolic effect in wild-type mice. Second, our analysis included dynamic histomorphometry, which enabled us to identify differential effects on bone formation caused by FTY720 administration. And third, since we applied the same strategy to S1pr3-deficient mice, we were able to show that the osteoanabolic effect of FTY720 administration is mediated through $\mathrm{S}_{1} \mathrm{P}_{3}$.

Although these results provide an important proof of principle for the therapeutic potential of S1P receptor stimulation in osteoporotic individuals, they do not directly translate into clinical applicability, since the dosage used for treatment of multiple sclerosis is much lower (up to $5 \mathrm{mg}$ per day) as compared with the animal experiments. Importantly, however, while it is unlikely that FTY720 itself could be applied for osteoanabolic treatment in humans, it might be a promising approach to develop selective $\mathrm{S}_{1} \mathrm{P}_{3}$ agonists and to analyse their potential for osteoporosis therapy. The osteoanabolic potential of S1P and its remarkable influence on bone remodelling is probably best underscored by the phenotype of Sgpl1 ${ }^{-1-}$ mice. These mice have been described to display high extracellular S1P levels causing various abnormalities and early postnatal lethality ${ }^{39}$. Moreover, a non-quantitative analysis of their skeletal phenotype demonstrated high bone mass, which was interpreted as osteopetrosis, that is, osteoclast dysfunction. Our histomorphometric analysis confirmed that the trabecular bone mass is dramatically increased in all Sgpl1-deficient mice reaching the age of 6 weeks (approximately 15\%). Importantly, however, the number of functionally active osteoclasts was significantly increased towards wild-type littermates, and the same was the case for serum PICP, indicating excessive bone formation. In conclusion, Sgpl1-deficient mice display high bone turnover triggering a progressive bone mass increase, which occurs despite the existence of various organ abnormalities. These findings are in full agreement with the suspected key role of S1P in bone remodelling and its ability to act as an osteoanabolic molecule.

Therefore, our collective findings do not only expand our current understanding of bone remodelling, they also identify two serpentine receptors specifically regulating bone formation. Since serpentine receptors represent the major class of target proteins for currently available drugs, it is conceivable to speculate that the development of CTR-specific antagonists and/or S1pr3-specific agonists might be a promising approach to counteract bone loss in osteoporosis or other skeletal disorders.

\footnotetext{
Methods

Mouse models. To obtain Calcr ${ }^{f l / f l}$ mice a targeting construct was generated, where we placed a Frt-neomycin-Frt-loxP cassette (kindly provided by G. Schuetz, Heidelberg, Germany) $5^{\prime}$ of exon 6 and a single loxP site $3^{\prime}$ of exon 7 , the latter one being inserted by ET recombination according to standard protocols. The construct was electroporated into embryonic stem cells R1, which were then screened for homologous recombination by Southern blotting following DNA digestion by Hind III. After removal of the neomycin resistance gene by electroporating a Flp-recombinase expression plasmid (kindly provided by G. Schuetz, Heidelberg, Germany), the targeted embryonic stem cells were injected in C57Bl/6J blastocysts
}

to generate chimeric mice, which were then crossed with $\mathrm{C} 57 \mathrm{Bl} / 6$ mice to obtain offspring with one floxed Calcr allele. These mice were either crossed to obtain Calcr ${ }^{f l f l}$ mice or with $C M V$-Cre transgenic mice, resulting in an ubiquitous recombination within the Calcr allele, as determined by Southern blotting or PCR genotyping using two primers flanking the loxP site between exons 7 and 8 (5' $5^{\prime}$ TCTGGGCTGCTGAGAAAGTATC- $3^{\prime}$ and $5^{\prime}$-ATGTGATTGGCTGGGCA CTG- $3^{\prime}$ ) and one primer located $5^{\prime}$ of the loxP site between exons 5 and 6 ( $5^{\prime}$-AAG ACAGATGGTGAGGGCTGACTG- $3^{\prime}$ ). The generation and genotyping of

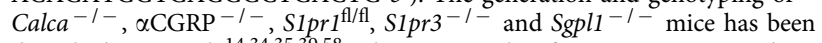
described previously $14,34,35,39,58$. The same applies for mice expressing the Cre recombinase under the control of different promoters ${ }^{22-24}$. For the confirmation of cell type-specific S1pr1 inactivation, a combination of primers ( $5^{\prime}$-GAGCGGAGGA AGTTAAAAGTG-3' ${ }^{\prime}$, ${ }^{\prime}$-CCTCCTAAGAGATTGCAGCAA- $3^{\prime}$ and $5^{\prime}$-GATCCTA AGGCAATGTCCTAGAATGGGACA- $3^{\prime}$ ) amplifying either the floxed or the recombined allele. To rule out a possible influence of genetic background, all in vivo analyses were performed with littermate controls. Although our initial analysis of the $\mathrm{Calcr}^{-1-}$ phenotype was done with 12 -week-old male and female mice, we used female mice for subsequent analyses with ages ranging from 3 weeks until 18 months, as indicated in the respective figure legends. Animal care and experimental procedures were performed with approval from the animal care committees of the University Medical Center Hamburg-Eppendorf.

Immunological protein detection. Immunohistochemistry was performed according to standard protocols using polyclonal antibodies against the rat CTR

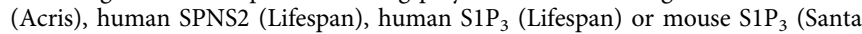
Cruz), all diluted 100-fold. Human bone sections were derived from decalcified iliac crest biopsies from an individual with M. Paget ${ }^{52}$, or from an autopsy case of a skeletal-intact donor. These studies were approved by the ethics committee of the Aerztekammer Hamburg. For immunohistochemistry the rehydrated sections were pretreated with $0.1 \%$ trypsin for $30 \mathrm{~min}$, and then incubated in $3 \%$ hydrogen peroxide for $15 \mathrm{~min}$ to block endogenous peroxidase activity. Incubation with $5 \%$ BSA for 30 min was subsequently performed to block nonspecific binding. Immunohistochemical staining with the primary antibodies was performed overnight at $4{ }^{\circ} \mathrm{C}$. Detection was achieved with a biotinylated secondary goat anti-rabbit IgG (1:200, Dako Cytomation) followed by incubation with a streptavidin/HRP (1:200, Dako Cytomation). Peroxidase activity was detected using $\mathrm{DAB}\left(3,3^{\prime}\right.$-diaminobenzidine tetrahydrochloride) as chromogenic substrate (Dako Cytomation). Sections were counterstained with hematoxylin, dehydrated and mounted. For western blotting, whole cells were lysed in RIPA buffer (1\% NP-40, $1 \%$ sodium desoxycholate, $0.1 \%$ sodium dodecylsulfate, $150 \mathrm{mM}$ sodium chloride, $2 \mathrm{mM}$ EDTA and $10 \mathrm{mM}$ sodium phosphate) or in CHAPS extraction buffer (50 mM Tris/Hcl pH 8.0, $150 \mathrm{mM} \mathrm{NaCl,} \mathrm{5 \%} \mathrm{glycerol,} \mathrm{1 \%} \mathrm{CHAPS,} 2 \mathrm{mM}$ EGTA, $1 \mathrm{mM}$ DTT) containing a protease and phosphatase inhibitor cocktail (Roche). Equal amounts of protein were separated on 12.5\% SDS-polyacrylamide gel electrophoresis and transferred to PVDF membranes (Hybond; GE Healthcare). After blocking with Tris-buffered saline containing 0.1\% Tween 20 and 5\% nonfat dry milk, membranes were incubated overnight at $4{ }^{\circ} \mathrm{C}$ with primary antibodies at a dilution of 1:1,000. The antibodies were directed against Spns2 (\#ARP56057; Avia Systems Biology), $\beta$-actin (\#MAB1501; Millipore), phospho-Erk1/2 (\#9101; Cell Signaling Technology), or Erk1/2 (\#4695; Cell Signaling Technology). Secondary HRP-conjugated antibodies (Dako) were used at a dilution of 1:5,000.

Cell culture. Primary osteoclasts were generated as described previously ${ }^{59}$. In brief, osteoclast precursor cells were isolated from the bone marrow of 12-week-old mice and differentiated for 4 days in $\alpha$-MEM containing $10 \mathrm{nM} 1,25(\mathrm{OH})_{2}$ Vitamin $\mathrm{D}_{3}$. For the next 6 days, they additionally received M-CSF $\left(20 \mathrm{ng} \mathrm{ml}^{-1}\right)$ and RANKL $\left(40 \mathrm{ng} \mathrm{ml}^{-1}\right)$ to allow terminal differentiation. The conditioned medium was collected from day 1-4 of culture (osteoclast precursor cells) or from day 7-10 of culture (mature osteoclasts). Primary osteoblasts were isolated by sequential collagenase digestion from the calvariae of 5-day-old mice and differentiated for 10 days in the presence of $25 \mu \mathrm{g} \mathrm{ml}^{-1}$ ascorbic acid and $5 \mathrm{mM} \beta$-glycerophosphate ${ }^{59}$ In some cases the culture medium contained $50 \%$ of conditioned medium from osteoclast precursor cells or mature osteoclasts (cultured either in the absence or in the presence of $10^{-7} \mathrm{M}$ CT for the last 4 days) as indicated. To monitor effects of $\mathrm{S} 1 \mathrm{P}$ on osteoblasts, bone marrow cells were differentiated for 10 days in the presence of $25 \mu \mathrm{g} \mathrm{ml}^{-1}$ ascorbic acid and $5 \mathrm{mM} \beta$-glycerophosphate with or without S1P $(1 \mu \mathrm{M})$. For short-term treatment, cells were serum-starved overnight and then stimulated with S1P $(1 \mu \mathrm{M})$ for $6 \mathrm{~h}$.

Cellular assays. For binding assays mature osteoclasts were incubated for $2 \mathrm{~h}$ with $10^{-11} \mathrm{M}^{125} \mathrm{I}$-salmon CT in the absence or presence of $10^{-8} \mathrm{M}$ salmon CT. Bound radioactivity was released by $0.5 \mathrm{M} \mathrm{NaOH}$ and quantified in a $\gamma$-counter. For resorption assays, bone marrow cells were plated on dentin slices and differentiated as described above (with CT added during the last 4 days). After staining with toluidine blue, the resorbed area was quantified using ImageTool software. TRAP activity staining was performed as described previously ${ }^{59}$. In brief, after removal of the medium and two washing steps with phosphate-buffered saline (PBS), cells were fixed with cold methanol for $5 \mathrm{~min}$. After washing and drying, they were stained with Naphthol AS-MX-Phosphate (Sigma) for $30 \mathrm{~min}$ before the number of 
TRAP-positive multinuclear cells per well was determined. For pathway analyses osteoclasts were pre-incubated with inhibitors of PLC (U-73122, Sigma, \#U6756; $10 \mu \mathrm{M})$, PKC (Chelerythrine chloride, Sigma, \#C2932; $10 \mu \mathrm{M})$ or PKA (H-89, Sigma, \#B1427; $300 \mathrm{nM}$ ) for $2 \mathrm{~h}$, followed by the stimulation with $10^{-7} \mathrm{M}$ CT for 6 h. Likewise, osteoblasts were pretreated with an Erk inhibitor (PD98059, Cell Signaling Technology \#9900, $50 \mu \mathrm{M}$ ) for $2 \mathrm{~h}$ before stimulation with $10^{-6} \mathrm{M} \mathrm{S1P}$ for $6 \mathrm{~h}$. For the assessment of matrix mineralization in primary osteoblast cultures, cells were stained after von Kossa, and the mineralized area was quantified using ImageTool software. For alizarin red staining, cells were incubated with $40 \mathrm{mM}$ alizarin red staining solution ( $\mathrm{pH}$ 4.2) for $10 \mathrm{~min}$ at room temperature after fixation in $90 \%$ ethanol. To quantify alizarin red incorporation cells were washed with PBS and fixed in $90 \%$ ethanol for $1 \mathrm{~h}$. After washing twice with distilled water, cells were stained with alizarin red S solution $(40 \mathrm{mM}, \mathrm{pH} 4.2)$ for $10 \mathrm{~min}$. Following additional washing steps with distilled water, the cell-bound alizarin red was dissolved in $10 \%$ acetic acid. After incubation for $30 \mathrm{~min}$ at room temperature and $10 \mathrm{~min}$ at $85^{\circ} \mathrm{C}$, the supernatant of a subsequent centrifugation step was neutralized with $10 \%$ ammonium hydroxide solution and the absorbance was measured at $405 \mathrm{~nm}$.

Biochemical assays. Analysis of mineral homeostasis, kidney function and determination of metabolic and hepatic parameters was carried out in the German Mouse Clinic as described ${ }^{60}$. All parameters were determined with a BeckmanCoulter AU 480 autoanalyzer, with the excecption of glycerol, which was measured using a kit from Randox Laboratories (Krefeld, Germany). Enzyme-linked immunosorbent assay was used to measure concentrations of collagen degradation products (Crosslaps, IDS), osteocalcin (Biomedical Technologies) and PICP (USCN Life Science). S1P concentrations were determined following HPLC analysis with all samples being collected in silicone-coated vessels ${ }^{61}$. The samples were transfered into siliconized glass tubes, internal standard was added and lipids were extracted by the addition of chloroform and methanol/HCl $(99.8: 0.2 \mathrm{v} / \mathrm{v})$ after prior alkalization by $3 \mathrm{~N} \mathrm{NaOH}$. The mixture was centrifuged $(300 \mathrm{~g}, 5 \mathrm{~min})$ to obtain the alkaline aqueous phase containing S1P. The organic phase was reextracted with methanol, $1 \mathrm{~N} \mathrm{NaCl}$ and $3 \mathrm{~N} \mathrm{NaOH}$. The combined aqueous phases were acidified by adding concentrated $\mathrm{HCl}$ and extracted twice with chloroform. The resulting organic phases were combined and evaporated by a vacuum system. The dried lipids were redissolved in methanol. Sample analyses were performed by rapid-resolution liquid chromatography-tandem mass spectrometry using an Agilent 1200 Series binary pump, a degasser and an autosampler (Agilent Technologies, Böblingen, Germany). A quadrupole time-of-flight 6530 mass spectrometer (QTOF) equipped with Jet-Stream technology operating in the positive electrospray ionization mode was used for detection (Agilent Technologies). High-purity nitrogen for the mass spectrometer was produced by a nitrogen generator (Parker Balston, Maidstone, UK). Chromatographic separations were obtained using a Waters X-Bridge C18 separation column $(4.6 \mathrm{~mm} \times 150 \mathrm{~mm}$, $3.5 \mu \mathrm{m}$ particle size, $138 \AA$ A pore size) with a Waters X-Bridge C18 guard column $(4.6 \times 20 \mathrm{~mm}$; Waters). We chose a binary solvent system with gradient elution consisting of eluent A (water/formic acid; 100:0.1 v/v); and eluent B (acetonitril/ tetrahydrofuran/formic acid; 50:50:0.1 v/v); and a flow rate of $0.5 \mathrm{ml} \mathrm{min}^{-1}$ over $15 \mathrm{~min}$. Mass spectrometric measurements were conducted using the following ion source conditions and gas settings for positive liquid chromatography-tandem mass spectrometry: sheath gas temperature $=300^{\circ} \mathrm{C}$; sheath gas flow $=91 \mathrm{~min}^{-1}$; nebulizer pressure $=30$ p.s.i.g.; drying gas temperature $=300^{\circ} \mathrm{C}$; drying gas flow $=81 \mathrm{~min}^{-1}$; capillary voltage $=5,400 \mathrm{~V}$; fragmentor voltage $=200 \mathrm{~V}$; nozzle voltage $=2,000 \mathrm{~V}$; and collision energy $=15 \mathrm{~V}$. Quantification was performed using MassHunter Software (Agilent Technologies). A calibration curve of analyte concentration was performed from 1-150 pmol and constructed by linear fitting using the least squares linear regression calculation. The resulting slope of the calibration curve was then used to calculate the concentration of the respective analyte in the unknowns.

Skeletal analysis. Before their skeletal analysis all mice were injected twice with calcein ( $30 \mathrm{mg} \mathrm{kg}^{-1}$ body weight) 9 and 2 days before sacrifice, which allowed a quantification of the bone formation rate by dynamic histomorphometry ${ }^{62}$. The dissected skeletons were fixed overnight in $4 \%$ formalin and then transformed into $80 \%$ ethanol, before an initial analysis by contact Xray was performed using a Faxitron Xray cabinet. The $\mu \mathrm{CT}$ scanning was performed using a Scanco $\mu \mathrm{CT} 40$ applying $55 \mathrm{kV}, 145 \mu \mathrm{A}$ and $200 \mathrm{~ms}$ integration time. Cortical bone was delineated and evaluated automatically using the image analysis algorithm provided by the manufacturer. The specific region for analysis of cortical thickness was a $1-\mathrm{mm}$ thick section of the central diaphysis. Bone mineral density in patients, after obtaining informed consent, were measured in spine and both femora using DEXA (GE Lunar Prodigy DF + 14622). In a subset of individuals structural bone parameters were determined in the left radius using high-resolution peripheral quantitative computed tomography (Scanco Medical xtremeCT). All blood parameters were determined by the Department of Clinical Chemistry. Exclusion criteria for the patient study were clinically apparent hypo- or hyperparathyroidism, Paget's disease of bone, impaired renal function, malignancies and metastatic bone disease, and bisphosphonate or teriparatide treatment.
Histology. Non-skeletal organs were histologically analysed in the German Mouse Clinic as described ${ }^{60}$. All organs were fixed in $4 \%$ buffered formalin before being embedded into paraffin. Sections of $2 \mu \mathrm{m}$ thickness were stained with haematoxylin and eosin according to standard protocols. For bone-specific analyses, dissected skeletons were fixed in 3.7\% PBS-buffered formaldehyde for $18 \mathrm{~h}$ and then transferred into $80 \%$ ethanol. Vertebral bodies L1 to L4 were dehydrated in ascending alcohol concentrations, before they were embedded into methylmethacrylate. Sections of $4 \mu \mathrm{m}$ thickness were cut in the sagittal plane using a Microtec rotation microtome. These were stained by von Kossa/van Gieson (for static hisotmorphometry) and toluidine blue (for cellular histomorphometry) staining procedures as described ${ }^{62}$. To determine the bone formation rate, all mice were injected twice with calcein 9 and 2 days before being killed. Static, cellular and dynamic histomorphometry at trabecular bone surfaces was carried out according to the guidelines of the American Society for Bone and Mineral Research ${ }^{63}$ using an OsteoMeasure system (Osteometrics Inc., USA). TRAP activity staining was performed on decalcified sections using Naphthol AS-MX-Phosphate (Sigma) and Fast Red Violet LB salt (Sigma) in $40 \mathrm{mM}$ acetate buffer ( $\mathrm{pH}$ 5).

Mice treatment. For induction of calvarial porosity, anaesthetized mice were injected with $10 \mathrm{mg} \mathrm{kg}^{-1}$ LPS (Escherichia coli O111:B4) onto their calvariae subcutaneously. After 6 days mice were killed and calvariae subjected to $\mu \mathrm{CT}$ analyses as described above. For quantification of the porosity the Axiovision software (Carl Zeiss) was used, while osteoclasts number was determined after TRAP activity staining as described above. Treatment of wild-type and S1pr3-deficient mice with FTY720 was performed in accordance to previous study ${ }^{40}$. More specifically 3 -month-old mice received daily intraperitoneal injections of FTY720 $\left(3 \mathrm{mg} \mathrm{kg}^{-1}\right.$ or $\left.6 \mathrm{mg} \mathrm{kg}^{-1}\right)$ or vehicle (PBS containing $5 \%$ acidified DMSO and 30\% BSA). After 4 weeks of treatment, the mice were analysed for their skeletal phenotype as described above.

Expression analysis. RNA was isolated using the RNeasyMini kit (Qiagen). For genome-wide expression analysis, $5 \mu \mathrm{g}$ of RNA were used for first-strand cDNA synthesis. For Gene Chip hybridization, the fragmented cRNA was incubated in hybridization solution at $45^{\circ} \mathrm{C}$ for $16 \mathrm{~h}$, before the Gene Chips (Affymetrix MG 430 2.0) were washed using the Affymetrix Fluidics Station 450. Microarrays were scanned with the Affymetrix Gene Chip Scanner 7G, and the signals were processed using GCOS(Affymetrix). The gene expression data have been deposited in GEO under accession code GSE60761. For RT-PCR expression analysis, $1 \mu \mathrm{g}$ of RNA was reversed transcribed using SuperScriptIII (Invitrogen) according to manufacturer's instructions. Gene-specific primers were used to amplify fragments of S1pr1 (5'-GGCTTATCTGGTCCCTCCTC- $3^{\prime}$ and $5^{\prime}$-CTTTGGCCTCAGCAA ATAGC- $\left.3^{\prime}\right)$, S1pr2 (5'-CCCCCTTCCATAAACAACCT- $3^{\prime}$ and $5^{\prime}$-CCCATACTGC CTCACCTGAT-3'), S1pr3 (5'-TCTGCTTTCACACAACAGCC-3'and 5'-GCAA GTAGCCAAGGTTGCTC- $\left.3^{\prime}\right)$, S1pr4 (5'-GCAGAAGTCTCCACGTCCTC- $3^{\prime}$ and $5^{\prime}$-GCTGAGTGACCGAGAAGTCC-3'), Sipr5 (5'-TATGGCTGCAGCAGAA ATTG- $3^{\prime}$ and $5^{\prime}$-TTCCTCTGTAGCCAGCCACT- $3^{\prime}$ ), and Gapdh (5'-GACATCAA GAAGGTGGTGAAGCAG- $3^{\prime}$ and $5^{\prime}$-CTCCTGTTATTATGGGGGTCTGG- ${ }^{\prime}$ ), respectively. For qRT-PCR expression analysis, $1 \mu \mathrm{g}$ of RNA was reversed transcribed using SuperScriptIII (Invitrogen) according to manufacturer's instructions qRT-PCR analysis (with Gapdh as internal control) was performed using predesigned TaqMan gene expression assays (Applied Biosystems), with the exception of Slpr2, where qRT-PCR was performed using SYBR green ( $5^{\prime}$-CGCAGGCTGGA GCTTAGGGC- ${ }^{\prime}$ and $5^{\prime}$-GCAGGAGCTGGGTGAGCTGC- ${ }^{\prime}$ ).

Statistical analysis. The number of samples was chosen according to established standards providing sufficient statistical power to enable the detection of biologically relevant differences in animal models. Mouse data were analysed by two-tailed Student's $t$-test using Excel software. All data are reported as mean \pm s.d. Human data were analysed using IBM SPSS Statistics 20. $P<0.05$ was considered statistically significant.

\section{References}

1. Zaidi, M. Skeletal remodeling in health and disease. Nat. Med. 13, 791-801 (2007).

2. Rachner, T. D., Khosla, S. \& Hofbauer, L. C. Osteoporosis: now and the future. Lancet 377, 1276-1287 (2011).

3. Copp, D. H. \& Cheney, B. Calcitonin-a hormone from the parathyroid which lowers the calcium-level of the blood. Nature 193, 381-382 (1962).

4. Foster, G. V. et al. Thyroid origin of calcitonin. Nature 202, 1303-1305 (1964)

5. Becker, K. L., Snider, R. \& Nylen, E. S. Procalcitonin in sepsis and systemic inflammation: a harmful biomarker and a therapeutic target. Br. J. Pharmacol 159, 253-264 (2010).

6. Lichtenstern, C., Brenner, T., Bardenheuer, H. J. \& Weigand, M. A. Predictors of survival in sepsis: what is the best inflammatory marker to measure? Curr. Opin. Infect. Dis. 25, 328-336 (2012).

7. Christopoulos, G. et al. Comparative distribution of receptors for amylin and the related peptides calcitonin gene related peptide and calcitonin in rat and monkey brain. Can. J. Physiol. Pharmacol. 73, 1037-1041 (1995). 
8. Marx, S. J., Woodward, C. J. \& Aurbach, G. D. Calcitonin receptors of kidney and bone. Science 178, 999-1001 (1972).

9. Chambers, T. J. \& Moore, A. The sensitivity of isolated osteoclasts to morphological transformation by calcitonin. J. Clin. Endocrinol. Metab. 57, 819-824 (1983)

10. Zaidi, M., Moonga, B. S. \& Abe, E. Calcitonin and bone formation: a knockout full of surprises. J. Clin. Invest. 110, 1769-1771 (2002).

11. Davey, R. A. \& Findlay, D. M. Calcitonin: physiology or fantasy? J. Bone Miner. Res. 28, 973-979 (2013)

12. Hirsch, P. F., Lester, G. E. \& Talmage, R. V. Calcitonin, an enigmatic hormone: does it have a function? J. Musculoskelet. Neuronal Interact. 1, 299-305 (2001).

13. Hurley, D. L., Tiegs, R. D., Wahner, H. W. \& Heath, 3rd H. Axial and appendicular bone mineral density in patients with long-term deficiency or excess of calcitonin. N. Engl. J. Med. 317, 537-541 (1987).

14. Hoff, A. O. et al. Increased bone mass is an unexpected phenotype associated with deletion of the calcitonin gene. J. Clin. Invest. 110, 1849-1857 (2002).

15. Huebner, A. K. et al. Calcitonin deficiency in mice progressively results in high bone turnover. J. Bone Miner. Res. 21, 1924-1934 (2006).

16. Schinke, T. et al. Decreased bone formation and osteopenia in mice lacking alpha-calcitonin gene-related peptide. J. Bone Miner. Res. 19, 2049-2056 (2004).

17. Lotinun, S. et al. Osteoclast-specific cathepsin K deletion stimulates S1Pdependent bone formation. J. Clin. Invest. 123, 666-681 (2013).

18. Pederson, L., Ruan, M., Westendorf, J. J., Khosla, S. \& Oursler, M. J. Regulation of bone formation by osteoclasts involves Wnt/BMP signaling and the chemokine sphingosine-1-phosphate. Proc. Natl Acad. Sci. USA 105, 20764-20769 (2008).

19. Dacquin, R. et al. Amylin inhibits bone resorption while the calcitonin receptor controls bone formation in vivo. J. Cell Biol. 164, 509-514 (2004).

20. Schwenk, F., Baron, U. \& Rajewsky, K. A cre-transgenic mouse strain for the ubiquitous deletion of loxP-flanked gene segments including deletion in germ cells. Nucleic Acids Res. 23, 5080-5081 (1995).

21. Sexton, P. M. et al. Procalcitonin has bioactivity at calcitonin receptor family complexes: potential mediator implications in sepsis. Crit. Care Med. 36, 1637-1640 (2008)

22. Casanova, E. et al. A CamKIIalpha iCre BAC allows brain-specific gene inactivation. Genesis 31, 37-42 (2001).

23. Clausen, B. E., Burkhardt, C., Reith, W., Renkawitz, R. \& Förster, I. Conditional gene targeting in macrophages and granulocytes using LysMcre mice. Transgenic Res. 8, 265-277 (1999).

24. Rauch, A. et al. Glucocorticoids suppress bone formation by attenuating osteoblast differentiation via the monomeric glucocorticoid receptor. Cell Metab. 11, 517-531 (2010).

25. Wada, S., Udagawa, N., Nagata, N., Martin, T. J. \& Findlay, D. M. Physiological levels of calcitonin regulate the mouse osteoclast calcitonin receptor by a protein kinase Alpha-mediated mechanism. Endocrinology 137, 312-320 (1996).

26. Yang, M. \& Kream, B. E. Calcitonin induces expression of the inducible cAMP early repressor in osteoclasts. Endocrine 33, 245-253 (2008).

27. Hisano, Y., Kobayashi, N., Kawahara, A., Yamaguchi, A. \& Nishi, T. The sphingosine 1-phosphate transporter, SPNS2, functions as a transporter of the phosphorylated form of the immunomodulating agent FTY720. J. Biol. Chem. 286, 1758-1766 (2011).

28. Kawahara, A. et al. The sphingolipid transporter spns 2 functions in migration of zebrafish myocardial precursors. Science 323, 524-527 (2009).

29. Ryu, J. et al. Sphingosine 1-phosphate as a regulator of osteoclast differentiation and osteoclast-osteoblast coupling. EMBO J. 25, 5840-5851 (2006)

30. Chakraborty, M., Chatterjee, D., Kellokumpu, S., Rasmussen, H. \& Baron, R Cell cycle-dependent coupling of the calcitonin receptor to different $G$ proteins. Science 251, 1078-1082 (1991).

31. Force, T. et al. A cloned porcine renal calcitonin receptor couples to adenylyl cyclase and phospholipase C. Am. J. Physiol. 262, F1110-F1115 (1992).

32. Chun, J., Hla, T., Lynch, K. R., Spiegel, S. \& Moolenaar, W. H. International Union of Basic and Clinical Pharmacology. LXXVIII. Lysophospholipid receptor nomenclature. Pharmacol. Rev. 62, 579-587 (2010).

33. Mutoh, T., Rivera, R. \& Chun, J. Insights into the pharmacological relevance of lysophospholipid receptors. Br. J. Pharmacol. 165, 829-844 (2012).

34. Allende, M. L., Yamashita, T. \& Proia, R. L. G-protein-coupled receptor S1P1 acts within endothelial cells to regulate vascular maturation. Blood 102, 3665-3667 (2003)

35. Ishii, I. et al. Selective loss of sphingosine 1-phosphate signaling with no obvious phenotypic abnormality in mice lacking its $\mathrm{G}$ protein-coupled receptor, LP(B3)/EDG-3. J. Biol. Chem. 276, 33697-33704 (2001)

36. Aubin, I. et al. A deletion in the gene encoding sphingomyelin phosphodiesterase 3 (Smpd3) results in osteogenesis and dentinogenesis imperfecta in the mouse. Nat. Genet. 37, 803-805 (2005).

37. Glorieux, F. H. Osteogenesis imperfecta. Best Pract. Res. Clin. Rheumatol. 22, 85-100 (2008)

38. Khavandgar, Z. et al. A cell-autonomous requirement for neutral sphingomyelinase 2 in bone mineralization. J. Cell Biol. 194, 277-289 (2011).
39. Vogel, P. et al. Incomplete inhibition of sphingosine 1-phosphate lyase modulates immune system function yet prevents early lethality and non-lymphoid lesions. PLoS ONE 4, e4112 (2009).

40. Ishii, M. et al. Sphingosine-1-phosphate mobilizes osteoclast precursors and regulates bone homeostasis. Nature 458, 524-528 (2009).

41. Potts, J. T. \& Gardella, T. J. Progress, paradox, and potential: parathyroid hormone research over five decades. Ann. N. Y. Acad. Sci. 1117, 196-208 (2007).

42. Overington, J. P., Al-Lazikani, B. \& Hopkins, A. L. How many drug targets are there? Nat. Rev. Drug Discov. 5, 993-996 (2006).

43. Huebner, A. K. et al. The role of calcitonin and alpha-calcitonin gene-related peptide in bone formation. Arch. Biochem. Biophys. 473, 210-217 (2008).

44. Davey, R. A. et al. Calcitonin receptor plays a physiological role to protect against hypercalcemia in mice. J. Bone Miner. Res. 23, 1182-1193 (2008).

45. Fiering, S. et al. Targeted deletion of 5'HS2 of the murine beta-globin LCR reveals that it is not essential for proper regulation of the beta-globin locus. Genes Dev. 9, 2203-2213 (1995).

46. Olson, E. N., Arnold, H. H., Rigby, P. W. \& Wold, B. J. Know your neighbors: three phenotypes in null mutants of the myogenic bHLH gene MRF4. Cell 85, 1-4 (1996)

47. Scacheri, P. C. et al. Bidirectional transcriptional activity of PGK-neomycin and unexpected embryonic lethality in heterozygote chimeric knockout mice. Genesis 30, 259-263 (2001).

48. Gooi, J. H. et al. Calcitonin impairs the anabolic effect of PTH in young rats and stimulates expression of sclerostin by osteocytes. Bone 46, 1486-1497 (2010).

49. Boyce, B. F. \& Xing, L. Osteoclasts, no longer osteoblast slaves. Nat. Med. 12, 1356-1358 (2006).

50. Martin, T., Gooi, J. H. \& Sims, N. A. Molecular mechanisms in coupling of bone formation to resorption. Crit. Rev. Eukaryot. Gene Expr. 19, 73-88 (2009).

51. Segovia-Silvestre, T. et al. Advances in osteoclast biology resulting from the study of osteopetrotic mutations. Hum. Genet. 124, 561-577 (2009).

52. Seitz, S. et al. Paget's disease of bone: histologic analysis of 754 patients. J. Bone Miner. Res. 24, 62-69 (2009).

53. Negishi-Koga, T. et al. Suppression of bone formation by osteoclastic expression of semaphorin 4D. Nat. Med. 17, 1473-1480 (2011).

54. Zhao, C. et al. Bidirectional ephrinB2-EphB4 signaling controls bone homeostasis. Cell Metab. 4, 111-121 (2006).

55. Fukuhara, S. et al. The sphingosine-1-phosphate transporter Spns2 expressed on endothelial cells regulates lymphocyte trafficking in mice. J. Clin. Invest. 122, 1416-1426 (2012).

56. Brinkmann, V. et al. Fingolimod (FTY720): discovery and development of an oral drug to treat multiple sclerosis. Nat. Rev. Drug Discov. 9, 883-897 (2010).

57. Chun, J. \& Hartung, H. P. Mechanism of action of oral fingolimod (FTY720) in multiple sclerosis. Clin. Neuropharmacol. 33, 91-101 (2010).

58. Lu, J. T. et al. Mice lacking alpha-calcitonin gene-related peptide exhibit normal cardiovascular regulation and neuromuscular development. Mol. Cell. Neurosci. 14, 99-120 (1999).

59. Schulze, J. et al. Interleukin-33 is expressed in differentiated osteoblasts and blocks osteoclast formation from bone marrow precursor cells. J. Bone Miner. Res. 26, 704-717 (2011).

60. Fuchs, H. et al. Mouse phenotyping. Methods 53, 120-135 (2011).

61. Nieuwenhuis, B. et al. Involvement of the ABC-transporter ABCC1 and the sphingosine 1-phosphate receptor subtype $\mathrm{S} 1 \mathrm{P}(3)$ in the cytoprotection of human fibroblasts by the glucocorticoid dexamethasone. J. Mol. Med. 87, 645-657 (2009)

62. Albers, J. et al. Canonical Wnt signaling inhibits osteoclastogenesis independent of osteoprotegerin. J. Cell Biol. 200, 537-549 (2013).

63. Parfitt, A. M. et al. Bone histomorphometry: standardization of nomenclature, symbols, and units. Report of the ASBMR Histomorphometry Nomenclature Committee. J. Bone Miner. Res. 2, 595-610 (1987).

\section{Acknowledgements}

We thank T. Zschaler, S. Perkovic, O. Winter, D. Reck and G. Arndt for technical assistance, as well as G. Schütz and T.J. Jentsch for providing plasmids and mice, respectively. We are particularly grateful to R.F. Gagel and R.B. Emeson for generating and providing Calca- and $\alpha$ CGRP-deficient mice, respectively. This work was supported by a grant from the Deutsche Forschungsgemeinschaft given to M.A. (AM103/15-1) and T.S. (SCHI-540-1) and by grants from the NIH given to J.C. (DA019674 and DC009505) Furthermore, this study was funded in part by the German Federal Ministry of Education and Research to the GMC (NGFN-Plus grants No. 01GS0850; 01GS0851; Infrafrontier grant 01KX1012).

\section{Authors contributions}

T.S. and M.A. designed the research. J.K., A.K.H., A.J., T.K., M.H., I.H-B. designed and performed experiments, P.C-L., A.L., M.K., J.A., J.S., S.S., H.D., T.H., M.N., T.S., S.B., F.B., B.R., E.W., J.C-W, F.N., V.G-D, H.F. M.HdA, E.T., L.C.H, B.K. analysed the data. B.L., S.K., J.C. contributed the reagents and analytic tools. 


\section{Additional information}

Accession codes: The genome-wide expression data set has been deposited in NCBI Gene Expression Omnibus under accession code GSE60761.

Supplementary Information accompanies this paper at http://www.nature.com/ naturecommunications

Competing financial interests: The authors declare no competing financial interests.

Reprints and permission information is available online at http://npg.nature.com/ reprintsandpermissions/
How to cite this article: Keller, J. et al. Calcitonin controls bone formation by inhibiting the release of sphingosine 1-phosphate from osteoclasts. Nat. Commun. 6:5215 doi: 10.1038/ncomms6215 (2014)

(c) (i) This work is licensed under a Creative Commons Attribution 4.0 International License. The images or other third party material in this
article are included in the article's Creative Commons license, unless indicated otherwise in the credit line; if the material is not included under the Creative Commons license, users will need to obtain permission from the license holder to reproduce the material. To view a copy of this license, visit http://creativecommons.org/licenses/by/4.0/ 